\title{
PLASMA MEMBRANE PORATING DOMAIN IN POLIOVIRUS 2B PROTEIN. A SHORT PEPTIDE MIMICS VIROPORIN ACTIVITY
}

Running Title: Membrane-porating non-structural protein domain

Key words: virus-host interactions; viroporin; enterovirus; pore-forming toxin; transmembrane domain; membrane permeability

Vanesa Madan ${ }^{1}$, Silvia Sánchez-Martínez ${ }^{2}$, Natascia Vedovato ${ }^{3}$, Giorgio Rispoli ${ }^{3}$, Luis Carrasco $^{1}$, and José L. Nieva ${ }^{2 *}$

${ }^{1}$ Centro de Biología Molecular (CSIC-UAM), Universidad Autónoma de Madrid, Canto Blanco, 28049 Madrid, Spain.

${ }^{2}$ Unidad de Biofísica (CSIC-UPV/EHU), Universidad del País Vasco, Aptdo. 644, 48080 Bilbao, Spain.

${ }^{3}$ CNISM, Dipartimento di Biologia ed Evoluzione, Sezione di Fisiologia e Biofisica, and Centro di Neuroscienze, Università di Ferrara, Via L. Borsari, 46, I-44100 Ferrara, Italy.

Corresponding author: José L. Nieva. Unidad de Biofísica (CSIC-UPV/EHU) and Departamento de Bioquímica, Universidad del País Vasco, Aptdo. 644, 48080 Bilbao, Spain. Phone: 3494 6013353/ Fax: 34946013360 E-mail: gbpniesj@,1g.ehu.es. 


\section{$\underline{\text { Summary }}$}

Picornavirus $2 \mathrm{~B}$, a non-structural protein required for effective viral replication, has been implicated in cell membrane permeabilization during the late phases of infection. Here, we have approached the molecular mechanism of this process by assessing the pore-forming activity of an overlapping peptide library that spanned the complete $2 \mathrm{~B}$ sequence. At non-cytopathic concentrations, only the $\mathrm{P} 3$ peptide, spanning $2 \mathrm{~B}$ residues 35-55, effectively assembled hydrophilic pores that allowed diffusion of low-molecular weight solutes across the cell plasma membrane $\left(\mathrm{IC}_{50} \approx 4 \times 10^{-7} \mathrm{M}\right)$ and boundary liposome bilayers (starting at peptide-to-lipid mole ratios $>1: 10^{4}$ ). Circular dichroism data were consistent with its capacity to fold as a helix in a membrane-like environment. Furthermore, addition of this peptide to a sealed plasma-membrane model, consisting of retinal rod outer segments patch-clamped in a whole-cell configuration, induced within seconds ion channel activity at concentrations as low as $10^{-8} \mathrm{M}$. Thus, we have established a "one-helix" 2B version that possesses the intrinsic pore-forming activity required to directly and effectively permeabilize the cell plasma membrane. We conclude that $2 \mathrm{~B}$ viroporin can be classified as a genuine pore-forming toxin of viral origin, which is intracellularly produced at certain times post-infection. 


\section{Introduction:}

Induction of non-selective pores in membranes constitutes an ancestral form of defense-offense adopted by a wide variety of organisms $1 ; 2 ; 3 ; 4 ; 5$. Cytolytic poreforming proteins and peptides targeting the plasma membrane of animal cells are produced by bacteria, vertebrates (as components of their immune systems), sea anemones, amoeba and fungi, and are also present in the venom of arthropods and snakes $1 ; 2 ; 4 ; 6 ; 7$. Although these cytotoxic polypeptides share little sequence homology, they almost invariably assemble into permeating structures that allow passive flux of ions and other solutes across membranes $1 ; 2 ; 8 ; 9$. To date, no functional homologs of viral origin similar to these ancient weapons have been discovered, even though enhanced membrane permeability is typically observed during infection of susceptible cells by most animal viruses ${ }^{10}$.

Membrane permeabilization, together with morphological alterations induced by virus replication such as nuclear modifications, disruption of the cytoskeletal network ${ }^{11 \text {; }}$ 12; 13 and the appearance of cytoplasmic membrane vesicles ${ }^{14 ; 15}$ have been collectively referred to as the cytopathic effect. In the case of naked viruses, intracellular accumulation of viral particles and/or massive expression of viral products have often been causally linked to non-specific membrane damage processes that are postulated to enhance permeability, cell lysis and ultimately release of new progeny ${ }^{16 ; 17}$. An alternative possibility in which specific, virally encoded products sustain this phenomenon was predicted many years ago $18 ; 19 ; 20$. The results of a variety of experiments pointed to the involvement of certain pore-like structures in the process. Membrane leakiness observed after the mid-phase of picornavirus infection was nonspecific for ions and small molecules (e.g., nucleotides, sugars, amino acids and 
inhibitors with a MW below 1,500 daltons), but not for macromolecules ${ }^{10}$. Moreover, individual expression of distinct viral genes was subsequently found to reproduce this process in several cell systems $21 ; 22 ; 23 ; 24 ; 25 ; 26 ; 27 ; 28 ; 29$. The name "viroporin" was proposed on observing that several virus proteins with potential permeabilizing activity might share common characteristics $26 ; 30 ; 31 ; 32$.

The picornavirus $2 \mathrm{~B}$ viroporin has received much attention for several reasons. First, picornaviruses provide an example of enhanced membrane permeability during the latter phases of the virus cycle ${ }^{19 ; 33 ; 34}$. Second, individual expression of $2 \mathrm{~B}$ induces plasma membrane permeabilization in mammalian cells, the effect being even stronger for $2 \mathrm{BC}$ precursor $21 ; 22 ; 23 ; 28 ; 32 ; 35 ; 36$. Third, the $2 \mathrm{~B}$ sequence bears two potential transmembrane domains (TMDs), which, although of modest hydrophobicity, might allow partitioning into membranes and oligomeric pore assembly $27 ; 29 ; 32 ; 37 ; 38$. Indeed, evidence for $2 \mathrm{~B}$ oligomerization at membrane surfaces has been obtained in culture cells and liposomes ${ }^{35 ; 37}$. Finally, a soluble and purified 2B fused to maltose binding protein (MBP-2B) induces liposome permeabilization to low-molecular weight solutes 37. Taken together, this evidence suggests a mechanism of membrane permeabilization similar to that of certain cytolytic toxins.

In the present work, we provide compelling evidence for the intrinsic capacity of poliovirus (PV) 2B viroporin to form stable, size-limited, non-selective pores at the cell plasma membrane. We have identified within a library that spanned the complete $2 \mathrm{~B}$ sequence a helical peptide that displayed 2B-like permeabilizing activity when added to cultured cells in the $\mathrm{nM}$ range concentration. Plasma membrane permeabilization was limited to low molecular-weight solutes, operated at 4 and $37^{\circ} \mathrm{C}$, and was inhibited by the external addition of impermeable streptavidin when biotinylated peptides were used. Direct and irreversible pore-formation on plasma membrane under physiological 
conditions was finally confirmed by a series of electrophysiological measurements, which revealed ion channel activity developing within seconds after applying directly the peptide onto a cell recorded in whole-cell configuration. We conclude that $2 \mathrm{~B}$ viroporin constitutes a new class of pore-forming protein that functions during infection as an intracellularly delivered toxin. Accordingly, we speculate that viroporin lytic domains might represent new potential leads for the development of bioactive peptides, and/or serve as targets for the development of antiviral compounds.

\section{Results:}

Mapping cell permeabilizing activity with a $2 B$ peptide library

Based on the fact that synthetic peptides representing a single helix may retain the capacity of the parental polypeptide sequences to assemble ion channels and pores

in membranes $39 ; 40 ; 41 ; 42$, we synthesized a library of soluble peptides (Table 1), and assayed them for their capacity to permeabilize cultured cells (Figure 1). Moreover, TMD mimics designed as soluble species have been used for the analysis of the specific in-membrane molecular recognition sustaining channel and surface receptor function ${ }^{43}$; 44; 45; 46 . Even if P3 bears an amphipathic character at its N-terminus, we found empirically that this sequence required at least 3 extra Lys residues to become a watersoluble species (not shown). Thus, both P3 and P5 peptides spanning 2B most hydrophobic regions (Figure 1A) included additional Lys-residues (Table 1) to yield the 
hydrophobicity of a range of previously described aqueous-soluble TMD sequences ${ }^{44 ;}$ 47.

The data shown in Figure 1B compare the abilities of the peptides to permeabilize cell monolayers. Single expression of $2 \mathrm{~B}$ from an alphavirus replicon induces entry of the translation inhibitor hygromycin B (HB) into BHK-21 cells, a process that can be monitored as a reduction in protein synthesis by the culture (righthand panel). Similarly, addition of P3 to the culture medium permeabilized cells to HB efficiently, whereas the rest of the peptide-library had virtually no effect, as was the case for untreated controls (left-hand panel). This trend in the cell monolayer permeabilization process induced by $2 \mathrm{~B}$ peptides was observed even with the highest concentration tested $(20 \mu \mathrm{M}$, not shown).

In our assays, the peptides partitioned from the aqueous medium into the membranes of culture cells. In order to estimate the capacity of each peptide to insert into the cell plasma membrane under these experimental conditions, their insertion into lipid monolayers was measured (Table 1). Estimation of the critical pressure for insertion (i.e., the surface pressure at which the sequences were excluded from the lipid monolayer, $\pi_{\mathrm{c}}$ ) indicated that the P3 capacity for insertion correlated with its permeabilizing activity. P5, which was unable to effectively permeabilize cells, also had a high capacity for insertion into membranes, while P4, comprising the sequence that connects P3 and P5, was clearly unable to penetrate at the surface pressures present in unstressed natural membranes $\left(\pi_{\mathrm{c}} \geq 30 \mathrm{mN} / \mathrm{m}\right)$.

Figure 2 displays the circular dichroism (CD) spectra of P3, P4 and P5 in the presence and absence of detergent micelles. These sequences behaved in opposing ways. P3 exhibited a certain degree of structuring in solution whereas P4 and P5 were largely unstructured. This finding suggests that P3 might form oligomers under these 
conditions. The observation that $\mathrm{P} 3 \mathrm{CD}$ spectra measured at 10 and $100 \mu \mathrm{M}$ concentration were similar, together with the fact that C-terminal Trp fluorescence increased linearly with increasing concentrations would be consistent with the existence of a predominant one-sized P3 oligomer (not shown).

P3 also adopted a highly $\alpha$-helical conformation in solutions containing sodium dodecyl sulfate (SDS), consistent with its further structuring in the membranemimicking detergent micelles ${ }^{44 ;}$. By comparison, P4 remained largely unstructured, while P5 helicity was modest in the presence of micelles. All the additional 2B peptides were unstructured in solution (not shown). Interestingly, amino-terminal P1 acquired certain degree of $\alpha$-helical conformation in the presence of SDS micelles, while P2 and P6 sequences became structured to a lesser extent (not shown).

Membrane permeabilization induced by $2 B$-derived P3 peptide in BHK-21 cells and liposomes

Together results in Figures 1 and 2 demonstrate that porating activity maps to an amphipathic-hydrophobic $2 \mathrm{~B}$ region (represented by $\mathrm{P} 3$ ), which is connected through a soluble sequence (represented by P4) with a second hydrophobic domain potentially able to insert into membranes (represented by P5). The data shown in Figures 3-5 compare in detail the abilities of P3 and P5 to permeabilize cell monolayers and lipid vesicles. Figure $3 \mathrm{~A}$ displays a titration experiment in which concentrations as low as 1 $\mu \mathrm{M}$ of $\mathrm{P} 3$ were enough to almost totally permeabilize cell cultures to HB. The dosedependent assays actually revealed an apparent $\mathrm{IC}_{50}$ of ca. $400 \mathrm{nM}$. P5, used as a 
specific negative control able to insert into membranes, did not significantly permeabilize cells at the highest concentrations tested (i.e., $10 \mu \mathrm{M}$ ).

To provide further evidence of the intrinsic capacity of P3 to form similar pores in pure lipid bilayers, we analyzed the entry of solutes into large unilamellar vesicles (LUV) after exposure to peptide (panel B). Entry of solutes was evaluated by calculating the percentage of N-(7-nitrobenz-2-oxa-1,3-diazol-4-yl) NBD reduced by externally added dithionite. In symmetrically labeled vesicles, this compound reduced NBD by approximately $50 \%$, as estimated from the decrease in fluorescence intensity (CTL in left-hand panel), indicating specific reduction of the probe residing in the external membrane leaflet. We thus took this value to represent a zero level of solute entry and assigned complete NBD reduction in detergent-solubilized vesicles the value of $100 \%$ entry. The data in Figure 3B (right-hand panel) clearly indicate that P3-bearing vesicles efficiently allowed the entry of solutes, whereas vesicles loaded with P5 were barely permeable to dithionite. P3-induced permeabilization reached its maximum extent at peptide-to-lipid mole ratios ( $\mathrm{Ri}-\mathrm{s})$ below 1:1000. Completion of the process at such low peptide doses suggests that permeabilization was not just a result of adding massive amounts of peptide to the vesicle membrane.

The results in Figure 4 support that permeabilization in this range of Ri-s developed through discrete structures of a limited size. In line with the phenomenon observed during the latter phases of PV infection, addition of P3 to cells did not make the plasma membrane permeable to the $\alpha$-sarcin (MW: 16000) macromolecule (panel A). Assembly of size-limited P3 pores at low membrane loads was confirmed assaying the leakage from LUV encapsulating solutes with different MW (panel B). Notably, P3 permeabilized vesicles to ANTS (MW: 425) at doses that did not induce any significant FD-4 (MW: 4000) or FD-10 (MW: 10000) release (Figure 4B, top panel). By 
comparison, vesicle permeabilization induced at a similar Ri by tetanolysin, a protein known to produce membrane lesions which allow the passage of macromolecules across membranes ${ }^{48}$, resulted in the simultaneous release to the medium of ANTS and FD-10 (slashed lines). Increasing P3 concentration induced some release of FD-4, while FD-10 was retained in the aqueous lumen of the liposomes (Figure 4B, bottom panel). This would be consistent with a maximal size of the P3 pore in the order of 20-25 $\AA^{49}$ under these conditions.

Overall, these observations suggest the presence in cell plasma and vesicle membranes of stable open aqueous channels with common characteristics (sequence specificity, solute size limit and stability). The fact that P3-induced permeabilization also occurred at $4^{\circ} \mathrm{C}$, a temperature at which receptor-mediated endocytosis is inhibited, reinforced this notion (Figure 5). Moreover, cell membranes remained permeabilized after removal of $\mathrm{P} 3$ from the medium and when cell cultures were allowed to return to normal temperature conditions $\left(37^{\circ} \mathrm{C}\right)$.

\section{P3 permeabilizing activity is inhibited at plasma membrane}

The effects described in the previous Figures 3-5 point to direct insertion into the lipid phase of the cell plasma membrane as responsible for the P3-induced permeabilization phenomenon. The localization of P3 at the plasma membrane was confirmed by confocal microscopy (Figure 6A), using binding of fluorescein-labeled streptavidin (Strep-FITC) to biotin attached at the peptide carboxy-terminus for detection. Inactive P5 sequence was localized to the same extent at the plasma membrane, again suggesting that plasma membrane-association alone was not enough to sustain cell permeabilization. The ability of impermeable streptavidin to bind the biotinylated peptide was subsequently exploited in order to test whether P3-induced cell 
permeabilization occurred at the level of the plasma membrane (Figure 6B). Incubation of both streptavidin and peptide in solution before addition to culture cells revealed an inhibitory effect of streptavidin on P3-induced permeabilization to HB (Protocol "a"). Moreover, this inhibitory effect was also observed when P3 was pre-incubated with cells to allow its insertion into membrane (Protocol "b").

Direct inhibition of biotinylated P3 by streptavidin was confirmed in pure lipid vesicles using similar protocols (Figure 6C). Streptavidin addition (indicated by the arrows) to the vesicles prior to peptide could inhibit the release of internal aqueous contents induced by P3 (panel a). The ongoing permeabilization process could be also arrested by adding streptavidin after the peptide (panel b). Thus, the fact that recognition of membrane-bound P3 by non-permeant streptavidin inhibited permeabilization is consistent with the idea that $\mathrm{P} 3$ established permeating pores at the surface of cells and liposomes. We surmise that the most likely explanation for the inactive streptavidin-peptide conjugate could be that binding of the peptide to streptavidin might prevent the creation of an oligomer and hence inhibit pore formation.

Fast and irreversible formation of P3 ion channels after addition to a natural plasma membrane

Electrophysiological measurements finally confirmed that P3-induced cell permeabilization was occurring through a direct pore-forming mechanism and not indirectly by affecting other cellular components (Figure 7). Kinetics of P3 ion channel formation was studied in the isolated retinal rod outer segments (OS) of amphibia (see Figure 7A). This system was selected because patch-clamped OS allow the detection of currents on a natural cell plasma membrane, i.e., under physiological conditions that preserve its lipid asymmetry and composition. 
Frog OS possess just two endogenous conductances: the light sensitive channels and the $\mathrm{Na}^{+}: \mathrm{Ca}^{2+}, \mathrm{K}^{+}$exchanger ${ }^{50 ; 51 ; 52}$. If the OS are illuminated, the light sensitive channels close; furthermore, the exchanger can be blocked by removing just one of the ion species that it transports $\left(\mathrm{Na}^{+}, \mathrm{Ca}^{2+}\right.$ or $\left.\mathrm{K}^{+}\right)$from both sides of the membrane. The exchanger current can be also reduced to negligible amplitudes by minimizing the electrochemical gradients of the transported ions. Under these conditions, the OS membrane resistance recorded in whole cells (Figure 7A) typically exceeded $1 \mathrm{G} \Omega$, allowing the detection of developing currents produced by the added peptides with high resolution (1 pA for a bandwidth of at least $1 \mathrm{kHz}$, Figure $7 \mathrm{~B}$ ).

The kinetics of ion channel formation after P3 and P5 addition was therefore tested as follows (Figures 7A and B). With the isolated OS continuously held at a fixed voltage $\left(V_{h}\right.$; range: $\left.-60-+60 \mathrm{mV}\right)$, the membrane resistance $\left(R_{m}\right)$ was measured before peptide perfusion. The peptide was then quickly applied $(<100 \mathrm{~ms})$ using a fast perfusion system (Figure 7A) and $R_{m}$ was measured again once the current had stabilized. The OS were finally returned to the control solution (without the peptide) to assess a possible recovery of the current.

No significant changes in current level or $R_{m}$ were induced by continuous perfusion of P5 (5 out of 5 OS) for up to 100 seconds at concentrations up to $1 \mu \mathrm{M}$ (Figure 7B, gray traces). In these experiments, $V_{h}$ was varied between -60 and $+60 \mathrm{mV}$ to rule out the possibility that the lack of ion channel formation was due to an inappropriate $V_{h}$. For instance, many peptides such as peptaibols permeabilize the membrane to ions when the intracellular side is held at a negative voltage ${ }^{53}$. In contrast, P3 was able to significantly permeabilize the OS plasma membrane to ions when applied at concentrations as low as $10 \mathrm{nM}$ (Table 2). Perfusion at $100 \mathrm{nM}$ for a few tens of seconds (typically $\sim 40 \mathrm{~s}$ ) permeabilized the OS plasma membrane to the extent that 
$R_{m}$ decreased by three orders of magnitude and became comparable to the access resistance in approximately one minute $\left(R_{a}\right.$, Figure $7 \mathrm{~B}$, black traces; see also Table 2$)$.

The increase in plasma membrane permeability to ions induced by the peptide can be quantitatively described in this system by kinetic parameters such as the "activation delay", defined as the time between peptide application and when a change of the current baseline larger than 3 times its average value occurs (indicated by the arrow in the inset of Figure 7B), and the current amplitude at steady-state. In the case of P3, at a fixed voltage $\left(V_{h}=-20 \mathrm{mV}\right)$, the activation delay and the current amplitude displayed inverse and direct relationships, respectively, with P3 concentration (Table 2). Both parameters were independent of $V_{h}$ over the range -60 to $+60 \mathrm{mV}$. Accordingly, the current to voltage relationship, measured once the current was stable with a voltage ramp from -60 to $+60 \mathrm{mV}$ (Figure $7 \mathrm{C}$ ), was linear and similar to that predicted by Ohm's law with a resistance approximately equal to $R_{m}(22 \mathrm{M} \Omega$ in the example of Figure 7C).

In order to evaluate P3 potency as an ion-channel former, its activity was compared to that of the standard $\alpha$-helical pore-forming peptide alamethicin ${ }^{54}$, measured under exactly the same experimental conditions (Figure 7D). Alamethicin addition induces ion channels in membranes through the self-association into rings of transmembrane helices $5 ; 55 ; 56$, which are very efficient at increasing conductance of artificial lipid bilayers ${ }^{57}$. Thus, the activation delay times for $1 \mu \mathrm{M}$ alamethicin assayed in the OS system was in the range of 2 seconds, a value lying in between those obtained for 0.1 and $1 \mu \mathrm{M}$ of $\mathrm{P} 3$, whereas the current amplitude at steady-state was roughly one third of that produced by $0.1 \mu \mathrm{M}$ of P3. Thus, in electrophysiological measurements of natural OS plasma membranes, P3 would be at least 10 times more potent than alamethicin as an ion-channel former. 


\section{$\underline{\text { Discussion }}$}

Membrane-porating proteins constitute an ancient element in defense-offense systems evolved by organisms of diverse origin ${ }^{1 ; 5}$. The results of our work provide the first experimental evidence that a non-structural viral protein from a naked virus is endowed with a functional pore-forming domain. This isolated PV 2B domain added to cell monolayers reproduces the permeabilization phenomenon observed after the midphase of cell infection by PV, i.e., diffusion of small solutes but not macromolecules across the membrane without any evident morphological degeneration accompanying the latter phases of the cytopathic effect. Our peptide-based approach also allowed specific mapping of this $2 \mathrm{~B}$ activity to the partially amphipathic $\mathrm{P} 3$ sequence (Figure 1). P5, representing a second transmembrane domain, also inserted into lipid monolayers and was located at the cell plasma membrane, but was devoid of the cell-permeabilizing activity of $\mathrm{P} 3$.

Our previous mutagenesis studies in the context of $2 \mathrm{~B}$ expressed in cells indicated that truncation of 30 amino acids at the amino-terminus severely impaired plasma membrane permeabilization by the protein ${ }^{21}$. This mutant was intracellularly synthesized by the translational machinery and subsequently transported to the site of permeabilization, while peptides in the present study were supplied exogenously and, therefore, had direct access to the plasma membrane. Only P3 was endowed with the capacity of permeabilizing the plasma membrane (panel B in Figure 1). Thus, from the combination of both approaches we propose now that deletion of the first 30 residues of 
2B may affect proper in-membrane folding and/or its trafficking along the vesicular system. Moreover, P1, P2 and P6 peptides became structured to some degree in SDS micelles and inserted into lipid monolayers at lateral pressures slightly above $30 \mathrm{mN} / \mathrm{m}$ (Table 1), suggesting that the $2 \mathrm{~B}$ sequences represented by these peptides might also play supportive functional roles in permeabilization, for instance as structural partners that ensure membrane insertion or regulate the pore-opening process.

The potency of the P3 sequence (active in the $\mathrm{nM}$ range) and the observation that the process is efficient in the absence of active transport (Figures 3 and 5) support the formation of channel-forming pores directly at the plasma membrane as the likely mechanism for P3-induced cell permeabilization. Furthermore, these pores are discrete and stable structures (i.e., they remain opened once they assemble and show a limiting size for the permeating solute) both in cells and lipid vesicles (Figures 3 and 4). In support of this view, biotinylated-P3 itself localizes at the plasma membrane and its action might be inhibited by external addition of streptavidin (Figure 6A) which, together with the fact that the peptide pores could be inhibited also in pure lipid vesicles (Figure 6B), is again indicative that cell permeabilization is mediated by P3 pores established directly in the lipid phase of the plasma membrane.

In the case of antimicrobial peptides it has been established a correlation between biological activity and binding and disrupting of model membranes ${ }^{58}$. In this regard, P3's behavior, namely, structuring in solution and capacity to permeabilize animal cell membranes and zwitterionic vesicles, parallels that of certain natural membranolytic peptides, such as cecropin-like human LL-37 $7^{59 ; 60}$, and synthetic species covalently linked to pre-form bundles ${ }^{61}$. Two main mechanisms have been proposed to

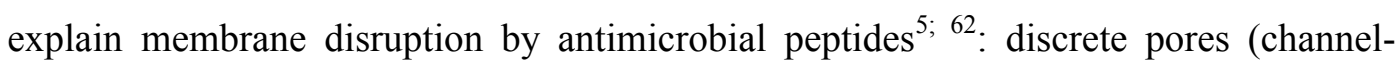
forming model) or detergent-like action (carpet model). Existence of a P3 discrete pore 
(either barrel-stave ${ }^{54}$ or toroidal ${ }^{63}$ type) is supported by its capacity to permeabilize electrically neutral bilayers to low-molecular weight solutes at doses ranging from 1:10.000 to $1: 1000$ peptide-to-lipid mole ratios. In comparison, cationic peptides permeabilizing vesicles via a detergent-like "carpet" mechanism require negatively charged phospholipids and substantially higher peptide-to-lipid mole ratios $5 ; 62 ; 64$.

The P3 pore hypothesis received conclusive support from electrophysiological measurements carried out on the frog OS model (Figure 7). This approach allowed the ion channel activity of P3 to be measured in a natural plasma membrane, i.e., under experimental conditions comparable to those in cell permeability assays. The measured activation delay times (arrow in the inset of Figure 7B) were in the order of few seconds, supporting that the assembly of P3 pores occurs directly at the plasma membrane. Moreover, in accordance with the results of experiments in cell and lipid vesicles that can sustain stable open structures, P3 irreversibly induced membrane currents when applied at low doses to OS. In comparison with alamethicin, a known amphipathic helical peptide that efficiently establishes "barrel-stave" channels in membranes $5 ; 55 ; 57$, P3 was approximately 10 times more potent at increasing OS membrane conductance.

The model in Figure 8 suggests possible structural correlations between P3 and 2B pores formed in the cell plasma membrane. Overall hydrophobic P3 sequence may attain in the external solution a periodic structure which exposes positively charged Lys residues in one of its sides (a), and subsequently self-assemble to shield the hydrophobic surfaces (b). In the resulting oligomeric P3 form (c) the amino-terminal end would be hydrophilic (pale grey surface), while the carboxy terminus would be overall hydrophobic (black). This degree of amphipathicity allows both, enough solubility and potential for association with the uncharged external plasma membrane 
monolayer through hydrophobic interactions. In the membrane-inserted state the charged residues reorient towards the lumen of an aqueous channel (d). In the 2BC precursor there exists the possibility of shielding hydrophobic sequences into the globular structure (e). Electrostatic interactions are probably important for its association with cell membrane monolayers topologically equivalent to the negatively charged internal monolayer of the plasma membrane. Several monomers are probably recruited at the membrane surface to establish an aqueous channel (f). In the latter oligomeric structure P3-P5 sequences would combine in each monomer to form a hairpin " $\alpha$-loop- $\alpha$ " motif so that both the $\mathrm{N}$ - and the C-terminal ends of the polypeptide remain at the same side of the membrane. In such a model the amphipathic P3 helix would serve to establish the interface between the lumen of the aqueous pore and the hydrophobic milieu of the membrane, adopting a topology reminiscent to that in the pore formed by the synthetic peptide (compare f and d).

However we caution that at this point we cannot rule out the existence of P3 topologies, different to membrane-spanning helices, which might be also lytic. In addition, the channel-forming model presented in Figure 8 does not discriminate between only-protein channels (barrel stave pore ${ }^{40 ; 62}$ ) or pores that are also participated by membrane phospholipids (toroidal pores ${ }^{56} 62 ; 63$ ). In the former case, ca. 10 monomers would participate in forming a pore with a diameter of 20-25 $\AA^{49}$ (not shown in the cartoon). Finally, as discussed above, it is likely that other regions of the $2 \mathrm{~B}$ stretch, including amino-terminal sequences and P5, also participate in the assembly of pores by the complete $2 \mathrm{BC}$ protein expressed during infection.

Taken together, our data demonstrate that 2B contains a structural motif that can by itself form permeating pores. Its efficacy, together with the observation that this region can cause direct permeabilization of the cell plasma membrane, suggests the 
existence of a selective pressure for the membrane-porating function. Pore-forming proteins are secreted by cytotoxic $\mathrm{T}$ lymphocytes and natural killer cells as a key component of a defensive response ${ }^{65}$. Perforin, related complement subunits and smaller polypeptides such as granulysin or NK-lysin are all released in close proximity to the target cell plasma membrane where they establish transmembrane pores $1 ; 66 ; 67 ; 68$; ${ }^{69}$. Several short peptides derived from the parental sequence as well as proteolytic fragments are able to reproduce perforin lytic activity, providing evidence that distinct core transmembrane domains are responsible for pore-formation ${ }^{42 ;} 70$. Thus, it may be that similar pore-forming motifs were co-opted during the course of evolution of certain viruses in order to induce cell death under conditions of cytopathic infection.

The precise function of $2 \mathrm{~B}$ during the $\mathrm{PV}$ infectious cycle has yet to be elucidated. Overexpressed 2B species accumulate in the endoplasmic reticulum and the Golgi apparatus, interfere with transport of glycoproteins to the cell surface, induce internal membrane restructuring and increase the levels of cytoplasmic calcium and other ions $21 ; 22 ; 23 ; 28 ; 35 ; 71$. Researchers have proposed that many if not all of these effects are a consequence of the membrane permeabilizing capacity of these species ${ }^{36}$. Thus, 2B-generated solute imbalance across cellular endomembranes might compromise organelle function, thereby creating suitable conditions for productive viral replication. Our studies support this possibility, while contributing to the knowledge of the $2 \mathrm{~B}$ non-selective pore architecture. 


\section{Concluding remarks}

Non-structural enterovirus $2 \mathrm{~B}$ has been postulated as an example of the viroporin family. These virally encoded proteins are postulated to compromise cell membrane permeability barriers ${ }^{30}$. The existence of a $2 \mathrm{~B}$ domain optimized for membrane-porating function would support the proposal that viroporins represent a new class of intracellular toxins. In addition, 2B-derived P3 encompasses a one-helix miniprotein with a high pore-forming potency. Hence, its activity in lipid vesicles could be used as a surrogate measure in screening for compounds that abrogate this activity. It was previously postulated that interfering with $2 \mathrm{~B}$ viroporin activity might block viral

replication as well as virus release ${ }^{28 ; 35}$. The present study provides the necessary framework to verify that hypothesis. A growing number of viruses that encode viroporin sequences have been described ${ }^{30}$. It will be of great interest to explore viroporins as a source of peptide-based structures to develop new bioactive compounds.

\section{Materials and Methods}

\section{Materials}

The poliovirus 2B-derived P1-P6 peptides displayed in Table 1 were produced by solidphase synthesis using Fmoc chemistry as C-terminal carboxamides and purified by HPLC. Phosphatidylcholine (PC) and N-(7-nitrobenz-2-oxa-1,3-diazol-4-yl) phosphatidylethanolamine (N-NBD-PE) were purchased from Avanti Polar Lipids (Birmingham, AL, USA). Fluorescein-conjugated streptavidin (streptavidin-FITC) and dextrans (FD-10 and FD-4), tetanolysin and alamethicin were supplied by Sigma (St. Louis, MO, USA). The 8-aminonaphtalene-1,3,6-trisulfonic acid sodium salt (ANTS) 
and p-xylenebis(pyridinium)bromide (DPX) were obtained from Molecular Probes (Junction City, OR, USA). All other reagents were of analytical grade.

\section{Circular Dichroism}

CD measurements were carried out on a thermally-controlled Jasco J-810 circular dichroism spectropolarimeter calibrated routinely with (1S)-(+)-10-camphorsulfonic acid, ammonium salt. Peptide stock samples consisted of lyophilized material dissolved in $2 \mathrm{mM}$ Hepes $(\mathrm{pH}, 7.4)$ at $0.03 \mathrm{mM}$. Spectra were measured in a $1 \mathrm{~mm}$ path-length quartz cell that was initially equilibrated at $25^{\circ} \mathrm{C}$. Data were taken with a $1 \mathrm{~nm}$ bandwidth at a scan rate of $20 \mathrm{~nm} / \mathrm{min}$, and the results of 5 scans were averaged.

\section{Cell assays}

Baby hamster kidney (BHK-21) cells were grown at $37^{\circ} \mathrm{C}$ in Dulbecco's modified Eagle medium (DMEM) supplemented with 5\% fetal calf serum (FCS) and non-essential amino acids. Peptide-induced membrane permeabilization was achieved by incubating BHK-21 cells with the peptides in FCS-free DMEM. Cells were subsequently treated with $1 \mathrm{mM} \mathrm{HB}$ or $10 \mu \mathrm{g} / \mathrm{ml} \alpha$-sarcin for $20 \mathrm{~min}$ at $37^{\circ} \mathrm{C}$. Proteins were then radiolabeled for 40 min with $10 \mu \mathrm{Ci}$ of $\left[{ }^{35} \mathrm{~S}\right]$ Met-Cys as previously described ${ }^{72}$. Protein synthesis was analyzed by SDS-PAGE and fluorography and quantified by densitometric scanning, using a GS-710 calibrated Imaging Densitometer (Bio-Rad). To establish the localization of biotinylated P3 and P5 peptides, BHK-21 cells seeded on glass cover slips were incubated with $1 \mu \mathrm{M}$ P3 or $1 \mu \mathrm{M}$ P5 for 1 hour at $37{ }^{\circ} \mathrm{C}$, and fixed with $4 \%$ paraformaldehyde. Cells were incubated with streptavidin-FITC at a dilution of 1:300 for 45 minutes at room temperature. Finally, the samples were mounted using 
mowiol/DABCO (Calbiochem) and analyzed in a Radiance 2000 (Bio-Rad/Zeiss) confocal laser scanning microscope.

\section{Lipid monolayer assays}

For the monolayer penetration assays, surface pressure was determined in a fixed-area circular trough ( $\mu$ Trough $\mathrm{S}$ system, Kibron, Helsinki) measuring $2 \mathrm{~cm}$ in diameter and with a volume of $1 \mathrm{ml}$. The aqueous phase consisted of $1 \mathrm{ml}$ of $5 \mathrm{mM}$ Hepes, $100 \mathrm{mM}$ $\mathrm{NaCl}$ ( $\mathrm{pH}$ 7.4). Lipids, dissolved in chloroform, were spread over the surface and the desired initial surface pressure $\left(\pi_{0}\right)$ was attained by changing the amount of lipid applied to the air-water interface. Peptides were injected into the subphase with a Hamilton microsyringe. At the concentrations used, the peptides alone induced a negligible increase in surface pressure at the air-water interface.

\section{Lipid vesicle assays}

Large unilamellar vesicles (LUV) of phosphatidylcholine were prepared according to the extrusion method in $5 \mathrm{mM}$ Hepes, $100 \mathrm{mM} \mathrm{NaCl}(\mathrm{pH}$ 7.4). Vesicle permeabilization was assayed by monitoring the release to the medium of encapsulated fluorescent ANTS

(ANTS/DPX assay ${ }^{73}$ ) or FITC-dextran probes, as previously described ${ }^{74}$. In a complementary assay, permeabilization was also assessed by monitoring the entry of dithionite into vesicles according to the method described by McIntyre and Sleight ${ }^{75}$, with the modifications introduced by Agirre et al. ${ }^{37}$. 


\section{Ion Channel activity}

Rod outer segments (OS) were mechanically isolated from the retina of dark adapted Rana esculenta individuals as described by Rispoli et al. ${ }^{51}$. OS were recorded using the whole-cell configuration of the patch-clamp technique under visual control (Fig. 7A) at room temperature $\left(20-22{ }^{\circ} \mathrm{C}\right)$, employing Axopatch 200B (Molecular Devices, Sunnyvale, CA, USA). The Ringer had the following composition (in $\mathrm{mM}$ ): $115 \mathrm{NaCl}, 3$ $\mathrm{KCl}, 10$ HEPES, $0.6 \mathrm{MgCl}_{2}, 0.6 \mathrm{MgSO}_{4}, 1.5 \mathrm{CaCl}_{2}, 10$ glucose (Osmolality 260 $\mathrm{mOsm} / \mathrm{Kg}$, buffered to $\mathrm{pH}=7.6$; all chemicals were purchased from Sigma Chemical Co.). The peak amplitude of the current transient elicited by $-5 \mathrm{mV}$ pulses (delivered at $10 \mathrm{~Hz}$ ) was used to measure access resistance $\left(R_{a}\right)$, whereas the current amplitude elicited by a $-10 \mathrm{mV}$ pulse during cell-attached and whole-cell recording was used to measure seal resistance and membrane resistance $\left(R_{m}\right)$, respectively.

After obtaining the whole cell recording, the cell was aligned in front of a multibarreled perfusion pipette that could be moved on a horizontal plane (Fig. 7A). Peptides were applied and removed in less than $100 \mathrm{~ms}$ by switching the OS back and forth from a stream of control perfusion solution (composition, in mM: $130 \mathrm{~K}^{+}, 1 \mathrm{Ca}^{2+}$ and 10 HEPES; Osmolality $260 \mathrm{mOsm} / \mathrm{Kg}$, buffered to $\mathrm{pH}=7.6$ ) to a stream containing the peptide (dissolved in the same perfusion solution). Patch pipettes were filled with the same perfusion solution to ensure the current was only driven by the holding voltage $\left(V_{h}\right)$. Every perfusion parameter of this computer controlled microperfusion system (developed in collaboration with De Angelis s.r.l., Genova, Italy) can be easily controlled by a user-friendly computer interface; minimal amounts of peptide solution $(<500 \mu \mathrm{l})$ were required to perform peptide applications lasting more than half an hour (typical perfusion speed: $15 \mu \mathrm{l} / \mathrm{min}$ ). 
Recordings were filtered at $2 \mathrm{kHz}$ via an eight-pole Butterworth filter (VBF/8 Kemo, Beckenham, UK), sampled on-line at $5 \mathrm{kHz}$ by a Digidata $1322 \mathrm{~A}$ connected to the SCSI port of a Pentium computer running the pClamp 9.0 software package (Molecular Devices, Sunnyvale, CA, USA). Figures and statistics were performed using SigmaPlot (Jandel Scientific, Sam Rafael, CA). The values presented in the text and figures are given as means \pm SEM.

\section{ACKNOWLEDGMENTS}

We wish to thank Miguel A. Sanz, Martina Infanti and Alberto Milani for their invaluable help with the experiments and data analysis and Dr. Gorka Basanez for fruitful discussions on the revision of the manuscript.

We acknowledge the financial support of the DGICYT project numbers BFU200602182/BMC (VM and LC) and BFU2005-06095/BMC (SSM and JLN). Further support to JLN was obtained from the Basque Government (AE2004-1-2) and the University of the Basque Country (042.310-13552). The CBM was awarded an institutional grant by the Fundación Ramón Areces. Financial support to GR included grants from the Ministero del'Università e della Ricerca (MIUR), Roma and from the "Comitato dei sostenitori dell'Università di Ferrara" (Project "Trasporto di carica fotoindotto in materiali funzionali"). 


\section{Figure legends}

\section{Figure 1: Non-structural Poliovirus 2B amino-acid sequence and analysis of}

membrane-permeabilizing activity in a peptide library. A) Direct translation of poliovirus positive RNA gives rise to a polyprotein precursor, which is subsequently processed through proteolysis to produce 3 protein intermediates. $2 \mathrm{~B}$ is one of the 3 nonstructural regulatory products that originate from further processing of the second intermediate (Top). The hydropathy plots above $2 \mathrm{~B}$ amino acid sequence correspond to mean hydrophobicity calculated using the Wimley-White octanol-water (O-W) partitioning scale for a sliding window of 11 amino acids and the moment in the $\alpha$ helical conformation (black and red-dotted traces, respectively). The blue plot displays the permeabilizing capacities of the 2B-derived peptides (Table 1). Values plotted for the center amino acid in each sequence correspond to levels of cell permeabilization (see below) induced by the peptides assayed at a concentration of $1 \mu \mathrm{M}$ (means \pm S.D., $\mathrm{n}=$ 3). B) Cell membrane permeabilization assay based on the reduction in protein synthesis induced by the externally added translation inhibitor hygromycin B (HB). Left: Cells were incubated with 2B P1-P5 peptides for $1 \mathrm{~h}$ before $\mathrm{HB}$ addition and then with $\left[{ }^{35} \mathrm{~S}\right] \mathrm{Met} / \mathrm{Cys}$ for $40 \mathrm{~min}$. Only P3-treated cells became permeable to the antibiotic. Untreated cells were not permeable to the antibiotic, and peptide addition per se did not affect protein biosynthesis. Right: control showing the membrane permeabilization induced by the complete $2 \mathrm{~B}$ protein expressed from "repC $+2 \mathrm{~B}$ " Sindbis virus (SV) replicon ${ }^{76}$. Most cells were efficiently transfected and so only expression of the SV capsid protein (C) and $2 \mathrm{~B}$ is detected. $\mathrm{C}$ expression does not affect membrane permeability as described previously ${ }^{76}$. 


\section{Figure 2: Structure of synthetic peptides derived from the $2 \mathrm{~B}$ hydrophobic region.}

CD spectra of P3, P4 and P5 peptides in buffer (dotted lines), and buffer containing 10 or $50 \mathrm{mM}$ SDS (slashed and continuous lines, respectively).

Figure 3: Permeabilization of BHK-21 cells and lipid vesicles by P3 and P5 peptides. A) Entry of solutes into BHK-21 cells. Left panel: Cells were incubated for 1 hour with $0.5-20 \mu \mathrm{M}$ of $\mathrm{P} 3$ and assayed for HB entry as reflected by the inhibition of protein synthesis (one representative experiment is shown). Right panel: Quantitation of the previous effect. P3-induced HB entry (circles and continuous line) was compared to that induced by P5 (squares and dotted line) (mean \pm S.D., $n=3$ ). B) Entry of solutes into peptide-permeabilized PC vesicles (dithionite assay). Left panel: NBD reduction by dithionite. CTL: PC:NBD-PE vesicles treated with dithionite (added at time $=30 \mathrm{~s}$, indicated by the arrow); P3 and P5: PC:NBD-PE vesicles preincubated with the respective peptides at 1:500 peptide-to-lipid ratio for $30 \mathrm{~min}$, and then treated with dithionite. Right panel: dithionite entry into PC vesicles $(50 \mu \mathrm{M})$ pre-loaded with P3 (circles and continuous line) or P5 (squares and dotted line) at different peptide:lipid molar ratios (Ri). Means \pm S.D. of 3 independent experiments are represented.

Figure 4: P3-induced permeabilization to solutes of different sizes. A) Cell membrane permeabilization to protein synthesis inhibitor $\alpha$-sarcin (MW: 16000). Positive control for $\alpha$-sarcin entry consisted in BHK-21 cells infected with SV at a multiplicity of infection of 10 or $100 \mathrm{pfu} / \mathrm{cell}$ as indicated. Cells became permeable to

this protein during viral entry ${ }^{72}$, but not after P3 addition. B) P3-induced leakage of 
solutes of different sizes encapsulated into PC vesicles. Top panel: Kinetic traces of release of ANTS (MW: 425), FD-4 (MW: 4000), and FD-10 (MW: 10000) were obtained at a 1:5000 P3:phospholipid molar ratio and $50 \mu \mathrm{M}$ lipid (continuous lines). The arrow indicates the peptide addition time. Slashed lines correspond to tetanolysin added to PC:Chol (1:1) vesicles at the same $\mathrm{Ri}$. This protein is reported to establish pores which allow passage of macromolecules across membranes ${ }^{48}$, and therefore induced simultaneous release of ANTS and FD-10 from liposomes. Bottom panel: Extent of P3-induced release of ANTS (circles and continuous trace), FD-4 (squares and slashed traces), and FD-10 (triangles and dotted trace) as a function of Ri.

Figure 5: Permeabilization by $\mathbf{P 3}$ at low temperature conditions. Cells preincubated at $4{ }^{\circ} \mathrm{C}$ were treated (or not) with $5 \mu \mathrm{M}$ P3 for $30 \mathrm{~min}$. HB entry was then tested or, alternatively, P3 peptide was removed and the cells were incubated for $90 \mathrm{~min}$ at $37^{\circ} \mathrm{C}$ in fresh medium. The numbers below each lane represent the percentages of protein synthesis of HB-treated cells compared with those corresponding to untreated cells (one representative experiment).

Figure 6: Localization and inhibition of $P 3$ at the cell surface. A) Binding of 2Bderived peptides to BHK-21 cell surface. Cells were either treated with $1 \mu \mathrm{M}$ biotinylated P3 or P5 for 1 hour, or left untreated. After fixation, cells were labeled with streptavidin-FITC (Strep-FITC) and analyzed in a confocal microscope. B) Inhibition of P3-induced cell permeabilization by streptavidin. Two protocols were followed: a) biotinylated P3 and streptavidin were pre-mixed and incubated for $15 \mathrm{~min}$ at $37{ }^{\circ} \mathrm{C}$ before addition to the culture cells; and b) cells were pre-treated with biotinylated P3 for 
15 min to allow its insertion into membranes (see Figure 5C) and then streptavidin was added. Cells were incubated for 1 hour with streptavidin:biotinylated P3 mixtures before being subjected to HB treatment. C) Inhibition of biotinylated P3-induced PC LUV permeabilization (ANTS leakage) by incubation with $0.1 \mu \mathrm{M}$ streptavidin (red traces), added before ("a" panel) or after ("b" panel) the onset of the process (addition times indicated by the arrows). The controls in the absence of streptavidin (black traces) were measured at 1:1000 peptide:lipid mole ratio and $50 \mu \mathrm{M}$ lipid.

Figure 7: Membrane conductance changes induced by 2B-derived P3 and P5 peptides on frog rod outer segments. A) Isolated rod outer segment (OS) recorded in whole-cell mode aligned in front of the multibarreled perfusion pipette. $(+)$ and $(-)$ arrows denote perfusion flows containing and not containing the peptide, respectively. The micrograph on the right shows the same cell at higher magnification. B) Kinetics of OS membrane permeabilization induced by P3 and P5. Black trace: current recorded during a 75 -second continuous perfusion of $100 \mathrm{nM} \mathrm{P} 3\left(V_{h}=-20 \mathrm{mV}\right.$ throughout the recording); Gray trace: another OS recorded under the same conditions but perfused with $1 \mu \mathrm{M}$ P5. The timing of peptide application is indicated by the line above the recordings. Inset: same traces as above, but smoothed to accurately measure the activation delay (indicated by the arrow, $4.8 \mathrm{~s}$ ), and the steady-state amplitude (1.1 nA); see text. $R_{m}$ before peptide application was measured from the current amplitude at -20 $\mathrm{mV}\left(-9.5 \mathrm{pA}, R_{m}=2.1 \mathrm{G} \Omega\right.$, black trace; $-27.0 \mathrm{pA}, R_{m}=0.8 \mathrm{G} \Omega$, gray trace; average: $1.8 \pm 0.9 \mathrm{G} \Omega, n=7)$. The $R_{m}$ following peptide application was measured once the current attained steady state by using short $(0.74 \mathrm{~s})$ and small $(-10 \mathrm{mV})$ voltage pulses (indicated by the asterisk on the gray trace) superimposed on $V_{h}$. At steady state, $R_{m}(22$ $\mathrm{M} \Omega$ ) became comparable to $R_{a}(12 \mathrm{M} \Omega)$ after P3 application, whereas it did not change 
significantly after perfusion of $1 \mu \mathrm{M}$ P5. C) Current to voltage relationship measured at the steady state with a voltage ramp from -60 to $+60 \mathrm{mV}$ (slope: $0.244 \mathrm{mV} / \mathrm{ms} ; V_{h}=-$ $20 \mathrm{mV}$ ). D) Comparison of delay times and current amplitudes induced by $0.1 \mu \mathrm{M}$ P3 (black bars), $1 \mu \mathrm{M}$ alamethicin (red bars) and $1 \mu \mathrm{M}$ P3 (blue bar).

Figure 8: Models for pores formed in cells by synthetic P3 and expressed 2BC (on top of and underneath the plasma membrane plane, respectively). In $2 \mathrm{BC}$, the grey ellipsoid denotes the globular 2C domain, while the grey cylinder would correspond to the sequence represented by P5. Membrane gaps exposing phospholipid acyl chains within pores are shown for better appreciation of P3 sequence topology, and would be covered either with protein residues (barrel-stave ${ }^{40 ; 62}$ ) or phospholipid polar head groups (toroidal pore ${ }^{62 ; 63 ; 77}$ ). See text for details. 


\section{$\underline{\text { References: }}$}

1. Ojcius, D. M. \& Young, J. D. (1991). Cytolytic pore-forming proteins and peptides: is there a common structural motif? Trends Biochem Sci 16, 225-9.

2. Parker, M. W. \& Feil, S. C. (2005). Pore-forming protein toxins: from structure to function. Prog Biophys Mol Biol 88, 91-142.

3. Gouaux, E. (1997). Channel-forming toxins: tales of transformation. Curr Opin Struct Biol 7, 566-73.

4. Wang, C. H. \& Wu, W. G. (2005). Amphiphilic beta-sheet cobra cardiotoxin targets mitochondria and disrupts its network. FEBS Lett 579, 3169-74.

5. Shai, Y. (1999). Mechanism of the binding, insertion and destabilization of phospholipid bilayer membranes by alpha-helical antimicrobial and cell nonselective membrane-lytic peptides. Biochim Biophys Acta 1462, 55-70.

6. Hecht, O., Van Nuland, N. A., Schleinkofer, K., Dingley, A. J., Bruhn, H., Leippe, M. \& Grotzinger, J. (2004). Solution structure of the pore-forming protein of Entamoeba histolytica. J Biol Chem 279, 17834-41.

7. Kuhn-Nentwig, L. (2003). Antmicrobial and cytolytic peptides of venomous arthropods. Cell Mol Life Sci 60, 2651-2668.

8. Gilbert, R. J. C. (2002). Pore-forming toxins. Cell Mol Life Sci 59, 832-844.

9. Panchal, R. G., Smart, M. L., Browser, D. N., Williams, D. A. \& Petrou, S. (2002). Pore-forming proteins and their application in biotechnology. Curr Farm Biotechnol 3, 99-115.

10. Carrasco, L. (1995). Modification of membrane permeability by animal viruses. Adv. Virus Res. 45, 61-112.

11. Castrillo, J. L. \& Carrasco, L. (1985). Increased inhibition of cellular RNA synthesis by $\alpha$-amanitin during entry of viruses into animal cells. FEMS Microbiol. Lett. 26, 221-225.

12. Doedens, J., Maynell, L. A., Klymkowsky, M. W. \& Kirkegaard, K. (1994). Secretory pathway function, but not cytoskeletal integrity, is required in poliovirus infection. Arch. Virol 136, 159-172.

13. Penman, S. (1965). Stimulation of the incorporation of choline in poliovirusinfected cells. Virology 25.

14. Penman, S. \& Summers, D. (1965). Effects on host cell metabolism following synchronous infection with poliovirus. Virology 27, 614-620.

15. Castrillo, J. L., Vanden-Berghe, D. \& Carrasco, L. (1986). 3-Methylquercetin is a potent and selective inhibitor of poliovirus RNA synthesis. . Virology 152, 219-227.

16. Carrasco, L. \& Castrillo, J. L. (1987). The regulation of translation in picornavirus-infected cells. In Mechanisms of viral toxicity in animal cells. (Carrasco, L., ed.), pp. 115-146. CRC Press, Boca-Raton, Florida. 
17. Koch, F. \& Koch, G. (1985). Morphological alterations of the host cell as an essential basis for poliovirus replication. In The Molecular Biology of Poliovirus, pp. 227-266. Springer Verlag, Wien.

18. Carrasco, L. (1978). Membrane leakiness after viral infection and a new approach to the development of antiviral agents. Nature 272, 694-9.

19. Carrasco, L. \& Smith, A. E. (1976). Sodium ions and the shut-off of host cell protein synthesis by picornaviruses. Nature 264, 807-9.

20. Carrasco, L. (1981). Modification of membrane permeability induced by animal viruses early in infection. Virology 113, 623-629.

21. Aldabe, R., Barco, A. \& Carrasco, L. (1996). Membrane permeabilization by poliovirus proteins 2B and 2BC. J Biol Chem 271, 23134-7.

22. Aldabe, R., Irurzun, A. \& Carrasco, L. (1997). Poliovirus protein 2BC increases cytosolic free calcium concentrations. $J$ Virol 71, 6214-7.

23. Barco, A. \& Carrasco, L. (1995). A human virus protein, poliovirus protein $2 \mathrm{BC}$, induces membrane proliferation and blocks the exocytic pathway in the yeast Saccharomyces cerevisiae. Embo J 14, 3349-64.

24. Barco, A. \& Carrasco, L. (1998). Identification of regions of poliovirus 2BC protein that are involved in cytotoxicity. $J$ Virol 72, 3560-70.

25. Doedens, J. R. \& Kirkegaard, K. (1995). Inhibition of cellular protein secretion by poliovirus proteins 2 B and 3A. Embo J 14, 894-907.

26. Madan, V., Garcia Mde, J., Sanz, M. A. \& Carrasco, L. (2005). Viroporin activity of murine hepatitis virus E protein. FEBS Lett 579, 3607-12.

27. van Kuppeveld, F. J., Galama, J. M., Zoll, J., van den Hurk, P. J. \& Melchers, W. J. (1996). Coxsackie B3 virus protein 2B contains cationic amphipathic helix that is required for viral RNA replication. $J$ Virol 70, 3876-86.

28. van Kuppeveld, F. J., Hoenderop, J. G., Smeets, R. L., Willems, P. H., Dijkman, H. B., Galama, J. M. \& Melchers, W. J. (1997). Coxsackievirus protein 2B modifies endoplasmic reticulum membrane and plasma membrane permeability and facilitates virus release. Embo J 16, 3519-32.

29. van Kuppeveld, F. J., Melchers, W. J., Kirkegaard, K. \& Doedens, J. R. (1997). Structure-function analysis of coxsackie B3 virus protein 2B. Virology 227, 1118.

30. Gonzalez, M. E. \& Carrasco, L. (2003). Viroporins. FEBS Lett 552, 28-34.

31. Carrasco, L., Perez, L., Irurzun, A., Martinez-Abarca, F., Rodriguez, P., Guinea, R., Castrillo, J. L., Sanz, M. A. \& Ayala, M. J. (1993). Modification of membrane permeability by animal viruses. In Regulation of Gene Expression in Animal Viruses (Carrasco, L., Sonenberg, N. \& Wimmer, E., eds.), pp. 283-305. Plenum Press, London.

32. Carrasco, L., Guinea, R., Irurzun, A. \& Barco, A. (2002). Effects of viral replication on cellular membrane metabolism and function. In Molecular biology of picornavirus (Semler, B. L. \& Wimmer, E., eds.), pp. 337-354. ASM Press, Washington. 
33. Carrasco, L., Otero, M. J. \& Castrillo, J. L. (1989). Modification of membrane permeability by animal viruses. Pharmacol Ther 40, 171-212.

34. Lacal, J. C. \& Carrasco, L. (1982). Relationship between membrane integrity and the inhibition of host translation in virus-infected mammalian cells. Comparative studies between encephalomyocarditis virus and poliovirus. Eur $J$ Biochem 127, 359-66.

35. de Jong, A. S., Melchers, W. J., Glaudemans, D. H., Willems, P. H. \& van Kuppeveld, F. J. (2004). Mutational analysis of different regions in the coxsackievirus 2B protein: requirements for homo-multimerization, membrane permeabilization, subcellular localization, and virus replication. $J$ Biol Chem 279, 19924-35.

36. de Jong, A. S., Visch, H. J., de Mattia, F., van Dommelen, M. M., Swarts, H. G., Luyten, T., Callewaert, G., Melchers, W. J., Willems, P. H. \& van Kuppeveld, F. J. (2006). The coxsackievirus 2B protein increases efflux of ions from the endoplasmic reticulum and Golgi, thereby inhibiting protein trafficking through the Golgi. J Biol Chem 281, 14144-50.

37. Agirre, A., Barco, A., Carrasco, L. \& Nieva, J. L. (2002). Viroporin-mediated membrane permeabilization. Pore formation by nonstructural poliovirus $2 \mathrm{~B}$ protein. J Biol Chem 277, 40434-41.

38. Nieva, J. L., Agirre, A., Nir, S. \& Carrasco, L. (2003). Mechanisms of membrane permeabilization by picornavirus $2 \mathrm{~B}$ viroporin. FEBS Lett 552, 6873.

39. Gazit, E., La Rocca, P., Sansom, M. S. \& Shai, Y. (1998). The structure and organization within the membrane of the helices composing the pore-forming domain of Bacillus thuringiensis delta-endotoxin are consistent with an "umbrella-like" structure of the pore. Proc Natl Acad Sci U S A 95, 12289-94.

40. Shai, Y. (1995). Molecular recognition between membrane-spanning polypeptides. Trends Biochem Sci 20, 460-4.

41. Stouffer, A. L., Nanda, V., Lear, J. D. \& DeGrado, W. F. (2005). Sequence determinants of a transmembrane proton channel: an inverse relationship between stability and function. J Mol Biol 347, 169-79.

42. Ojcius, D. M., Persechini, P. M., Zheng, L. M., Notaroberto, P. C., Adeodato, S. C. \& Young, J. D. (1991). Cytolytic and ion channel-forming properties of the $\mathrm{N}$ terminus of lymphocyte perforin. Proc Natl Acad Sci U S A 88, 4621-5.

43. Partridge, A. W., Melnyk, R. A. \& Deber, C. M. (2002). Polar residues in membrane domains of proteins: molecular basis for helix-helix association in a mutant CFTR transmembrane segment. Biochemistry 41, 3647-53.

44. Partridge, A. W., Melnyk, R. A., Yang, D., Bowie, J. U. \& Deber, C. M. (2003). A transmembrane segment mimic derived from Escherichia coli diacylglycerol kinase inhibits protein activity. $J$ Biol Chem 278, 22056-60.

45. Popot, J. L. \& Saraste, M. (1995). Engineering membrane proteins. Curr Opin Biotechnol 6, 394-402.

46. Therien, A. G. \& Deber, C. M. (2002). Oligomerization of a peptide derived from the transmembrane region of the sodium pump gamma subunit: effect of the pathological mutation G41R. J Mol Biol 322, 583-50. 
47. Melnyk, R. A., Partridge, A. W., Yip, J., Wu, Y., Goto, N. K. \& Deber, C. M. (2003). Polar residue tagging of transmembrane peptides. Biopolymers 71, 67585.

48. Rottem, S., Cole, R. M., Habig, W. H., Barile, M. F. \& Hardegree, M. C. (1982). Structural characteristics of tetanolysin and its binding to lipid vesicles. $J$ Bacteriol 152, 888-92.

49. Ladokhin, A. S., Selsted, M. E. \& White, S. H. (1997). Sizing membrane pores in lipid vesicles by leakage of co-encapsulated markers: pore formation by melittin. Biophys J 72, 1762-6.

50. Rispoli, G. (1998). Calcium regulation of phototransduction in vertebrate rod outer segments. $J$ Photochem Photobiol B 44, 1-20.

51. Rispoli, G., Sather, W. A. \& Detwiler, P. B. (1993). Visual transduction in dialysed detached rod outer segments from lizard retina. $J$ Physiol 465, 513-37.

52. Moriondo, A. \& Rispoli, G. (2003). A step-by-step model of phototransduction cascade shows that $\mathrm{Ca} 2+$ regulation of guanylate cyclase accounts only for short-term changes of photoresponse. Photochem Photobiol Sci 2, 1292-8.

53. Toniolo, C., Crisma, M., Formaggio, F., Peggion, C., Epand, R. F. \& Epand, R. M. (2001). Lipopeptaibols, a novel family of membrane active, antimicrobial peptides. Cell Mol Life Sci 58, 1179-1188.

54. Rinehart, K. L., Jr., Cook, J. C., Jr., Meng, H., Olson, K. L. \& Pandey, R. C. (1977). Mass spectrometric determination of molecular formulas for membranemodifying antibiotics. Nature 269, 832-3.

55. Epand, R. M. \& Vogel, H. J. (1999). Diversity of antimicrobial peptides and their mechanisms of action. Biochim Biophys Acta 1462, 11-28.

56. Huang, H. W. (2006). Molecular mechanism of antimicrobial peptides: the origin of cooperativity. Biochim Biophys Acta 1758, 1292-1302.

57. Duclohier, H. \& Wroblewski, H. (2001). Voltage-dependent pore formation and antimicrobial activity by alamethicin and analogues. J Membr Biol 184, 1-12.

58. Papo, N. \& Shai, Y. (2003). Can we predict biological activity of antimicrobial peptides from their interactions with model phospholipid membranes? Peptides 24, 1693-703.

59. Oren, Z., Lerman, J. C., Gudmundsson, G. H., Agerberth, B. \& Shai, Y. (1999). Structure and organization of the human antimicrobial peptide LL-37 in phospholipid membranes: relevance to the molecular basis for its non-cellselective activity. Biochem J 341 ( Pt 3), 501-13.

60. Durr, U. H., Sudheendra, U. S. \& Ramamoorthy, A. (2006). LL-37, the only human member of the cathelicidin family of antimicrobial peptides. Biochim Biophys Acta 1758, 1408-25.

61. Sal-Man, N., Oren, Z. \& Shai, Y. (2002). Preassembly of membrane-active peptides is an important factor in their selectivity toward target cells. Biochemistry 41, 11921-30.

62. Sato, H. \& Feix, J. B. (2006). Peptide-membrane interactions and mechanisms of membrane destruction by amphipathic alpha-helical antimicrobial peptides. Biochim Biophys Acta 1758, 1245-56. 
63. Sobko, A. A., Kotova, E. A., Antonenko, Y. N., Zakharov, S. D. \& Cramer, W. A. (2006). Lipid dependence of the channel properties of a colicin E1-lipid toroidal pore. J Biol Chem 281, 14408-16.

64. Ladokhin, A. S. \& White, S. H. (2001). 'Detergent-like' permeabilization of anionic lipid vesicles by melittin. Biochim Biophys Acta 1514, 253-60.

65. Trapani, J. \& Smyth, M. (2002). Functional significance of the perforin/ granzyme cell death pathway. Nat Rev Immunol 2, 735-747.

66. Anderson, D. H., Sawaya, M. R., Cascio, D., Ernst, W., Modlin, R., Krensky, A. \& Eisenberg, D. (2003). Granulysin crystal structure and a structure-derived lytic mechanism. J Mol Biol 325, 355-65.

67. Andersson, M., Gunne, H., Agerberth, B., Boman, A., Bergman, T., Sillard, R., Jornvall, H., Mutt, V., Olsson, B., Wigzell, H. \& et al. (1995). NK-lysin, a novel effector peptide of cytotoxic T and NK cells. Structure and cDNA cloning of the porcine form, induction by interleukin 2, antibacterial and antitumour activity. Embo J 14, 1615-25.

68. Liepinsh, E., Andersson, M., Ruysschaert, J. M. \& Otting, G. (1997). Saposin fold revealed by the NMR structure of NK-lysin. Nat Struct Biol 4, 793-5.

69. Voskoboinik, I. \& Trapani, J. (2006). Addressing the mysteries of perforin function Immunol Cell Biol 84, 66-71.

70. Baran, K., Ciccone, A., Peters, C., Yagita, H., Bird, P. I., Villadangos, J. A. \& Trapani, J. A. (2006). Cytotoxic T lymphocytes from cathepsin B-deficient mice survive normally in vitro and in vivo after encountering and killing target cells. J Biol Chem 281, 30485-30491.

71. Sandoval, I. V. \& Carrasco, L. (1997). Poliovirus infection and expression of the poliovirus protein $2 \mathrm{~B}$ provoke the disassembly of the Golgi complex, the organelle target for the antipoliovirus drug Ro-090179. J Virol 71, 4679-93.

72. Madan, V., Sanz, M. A. \& Carrasco, L. (2005). Requirement of the vesicular system for membrane permeabilization by Sindbis virus. Virology 332, 307-15.

73. Ellens, H., Bentz, J. \& Szoka, F. C. (1985). H+- and Ca2+-induced fusion and destabilization of liposomes. Biochemistry 24, 3099-106.

74. Basanez, G., Zhang, J., Chau, B. N., Maksaev, G. I., Frolov, V. A., Brandt, T. A., Burch, J., Hardwick, J. M. \& Zimmerberg, J. (2001). Pro-apoptotic cleavage products of $\mathrm{Bcl}-\mathrm{xL}$ form cytochrome c-conducting pores in pure lipid membranes. J Biol Chem 276, 31083-91.

75. McIntyre, J. C. \& Sleight, R. G. (1991). Fluorescence assay for phospholipid membrane asymmetry. Biochemistry 30, 11819-27.

76. Sanz, M. A., Madan, V., Carrasco, L. \& Nieva, J. L. (2003). Interfacial domains in Sindbis virus $6 \mathrm{~K}$ protein. Detection and functional characterization. $J$ Biol Chem 278, 2051-7.

77. Huang, H. W. (2004). Molecular mechanisms of peptide-induced pores in membranes. Phys. Rev. Lett. 92, 198304. 
Table 1: Designation of $2 \mathrm{~B}$ peptides and their insertion capacities in a membrane environment.

\begin{tabular}{|c|c|c|}
\hline Peptide & Sequence & $\boldsymbol{\pi}_{\mathbf{c}}(\mathbf{m N} / \mathbf{m})$ \\
\hline P1 & 1GITNYIESLGAAFGSGFTQQIS22 & 33.2 \\
\hline P2 & 23DKITELTNMVTSTITEKLLKNLIK46 & 32.9 \\
\hline P3 & K-35TITEKLLKNLIKIISSLVIIT55-WKK & 44.1 \\
\hline P4 & 46KIISSLVIITRNYEDTTTVLAT67 & $<25$ \\
\hline P5 & KKK- & 37.9 \\
\hline P6 & 74DASPWQWLRKKACDVLEIPYVIKQ97 & 32.6 \\
\hline
\end{tabular}

1: Capacities for penetration into membranes. Critical surface pressures for insertion into a PC monolayer are given. 
Table 2: Parameters obtained from the kinetics of P3-induced OS membrane conductance increase at different concentrations.

\begin{tabular}{|c|c|c|c|c|c|}
\hline$[\mathrm{P} 3] \mathrm{nM}$ & Delay (s) & $\begin{array}{c}\text { Amplitude } \\
(\mathrm{nA})\end{array}$ & $\begin{array}{c}R_{m} \text { before } \\
(\mathrm{G} \Omega)\end{array}$ & $\begin{array}{c}R_{m} \text { after } \\
(\mathrm{M} \Omega)\end{array}$ & $\begin{array}{c}R_{a} \\
(\mathrm{M} \Omega)\end{array}$ \\
\hline $33(n=3)^{1}$ & $9.9 \pm 2.6$ & $0.22 \pm 0.08$ & $1.3 \pm 0.3$ & $110 \pm 40$ & $18 \pm 7$ \\
\hline $100(n=5)$ & $5.2 \pm 0.7$ & $1.0 \pm 0.3$ & $2.0 \pm 0.8$ & $29 \pm 14$ & $17 \pm 8$ \\
\hline $1000(n=3)$ & $0.5 \pm 0.2$ & $\mathrm{nd}^{2}$ & $1.2 \pm 0.5$ & $\mathrm{nd}^{\mathrm{b}}$ & $18 \pm 8$ \\
\hline
\end{tabular}

1: " $\mathrm{n}$ " indicates average number of OS

2: at this P3 concentration $R_{m}$ became smaller than $R_{a} . R_{m}$ could not be measured and the steady state amplitude was meaningless. 
A

Non structural proteins

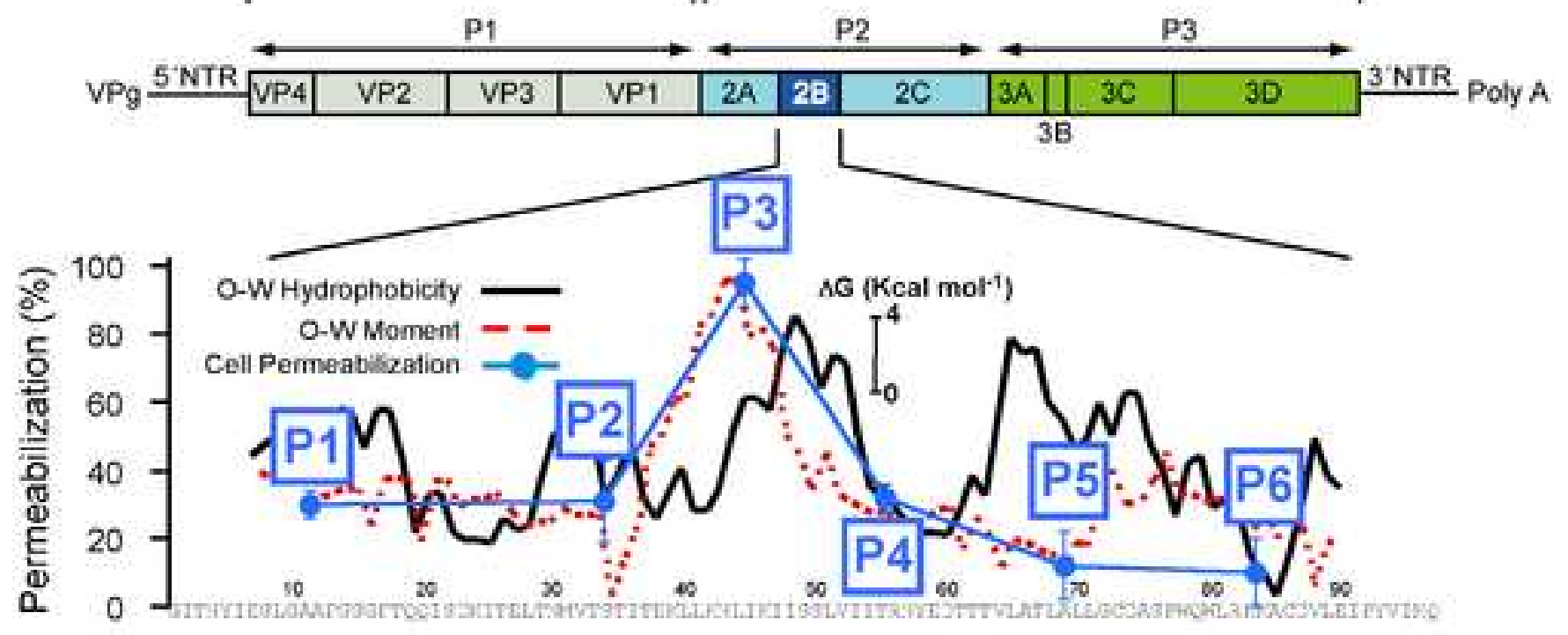

B

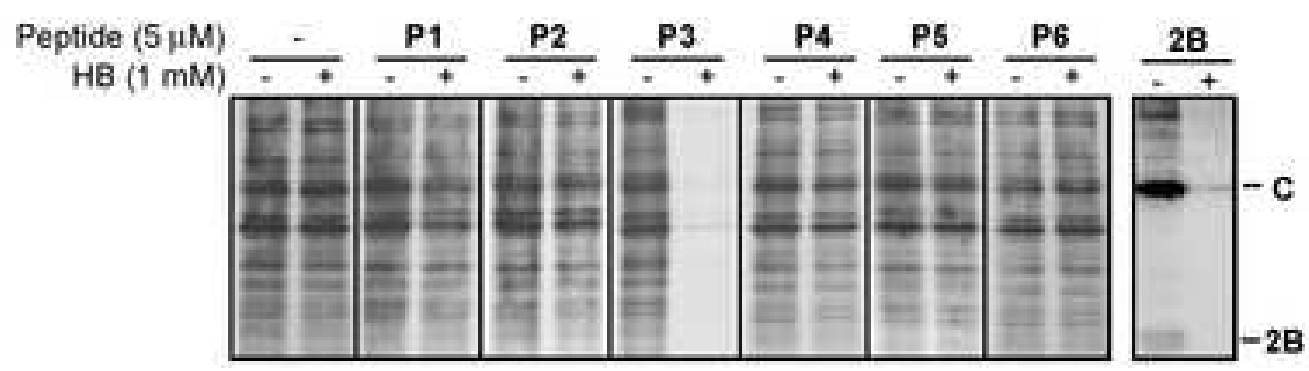



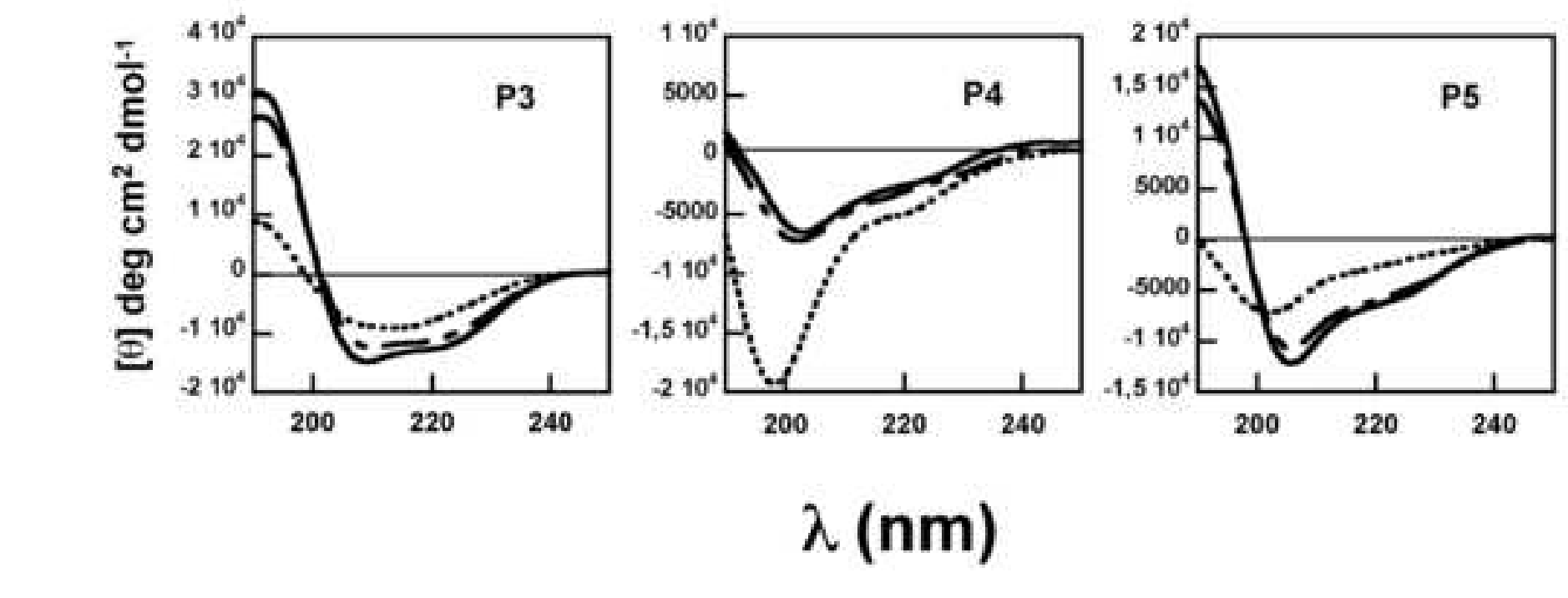

Clck here to download high resolution image

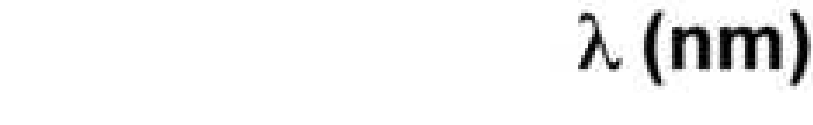

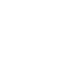

\author{
Figure2
Click here to download high resolution image
}

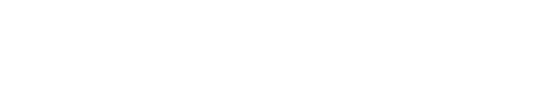

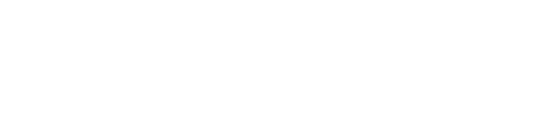


Click here to download high resolution image
Clice 3

A

\section{BHK-cells}
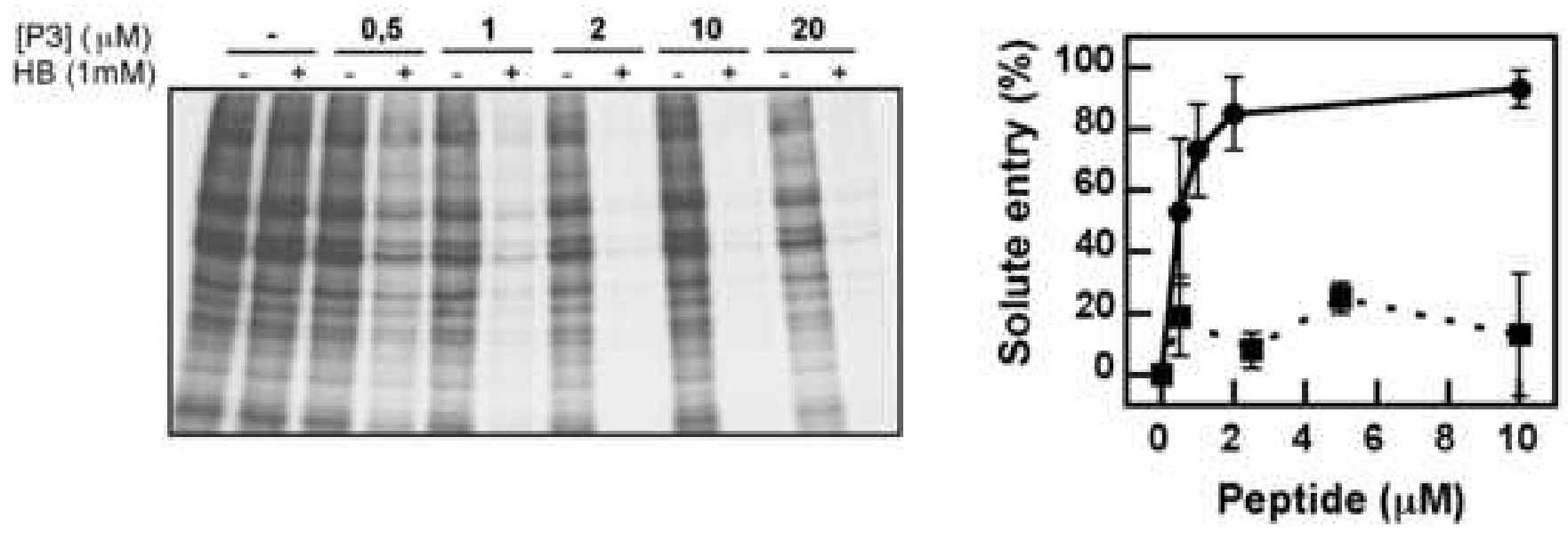

B

\section{Liposomes}
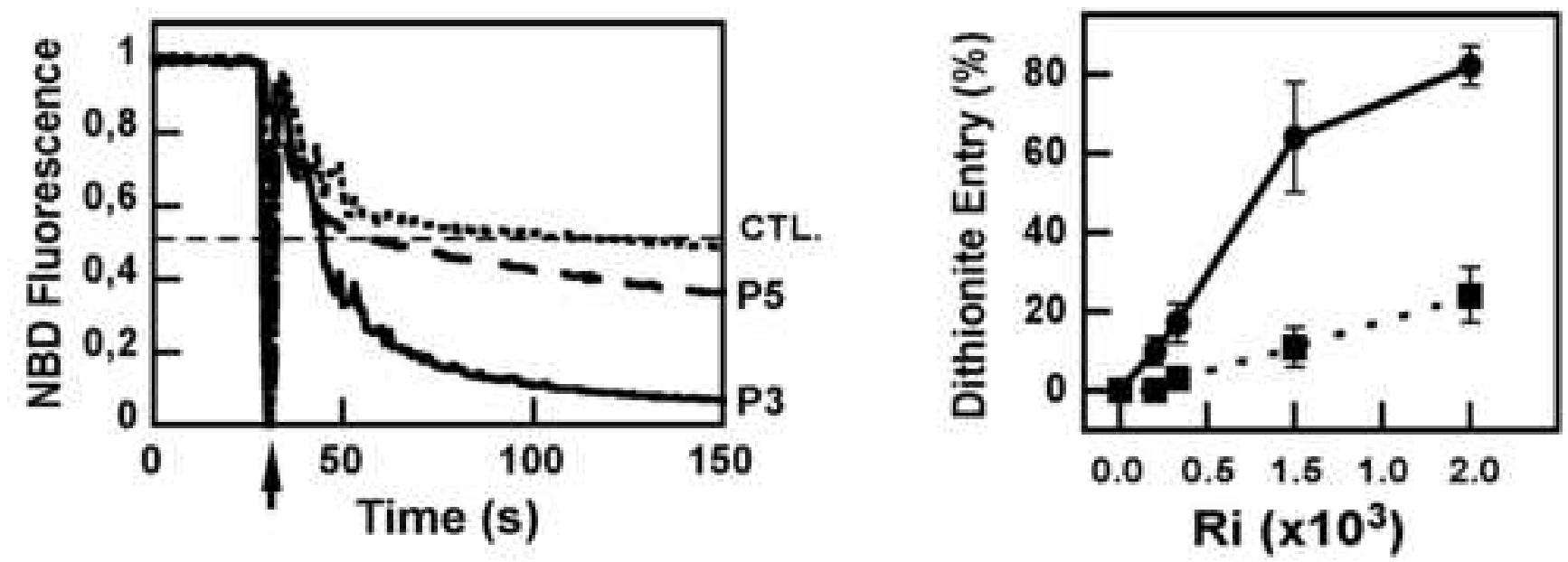
Figure4

Click here to download high resolution image
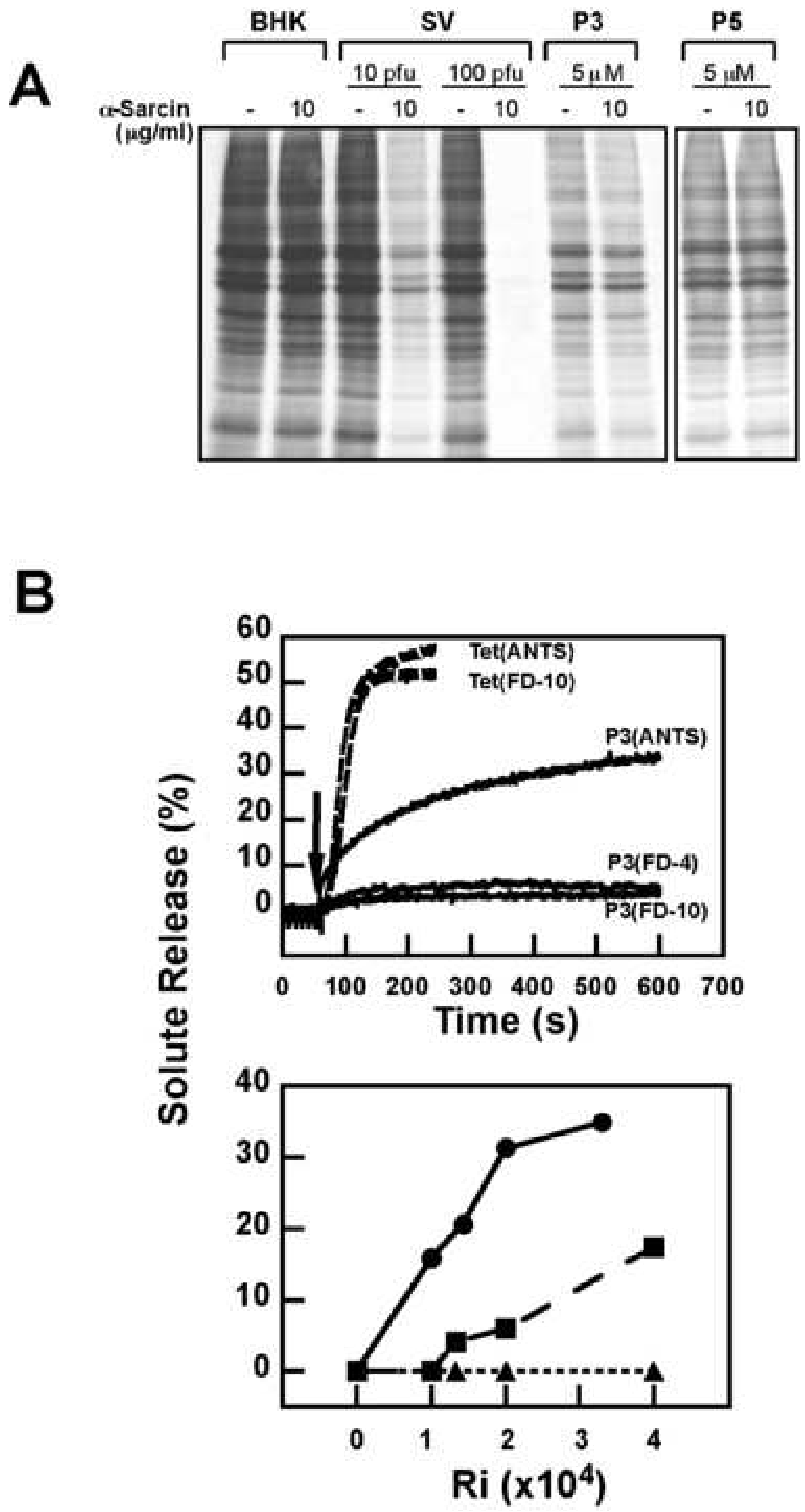
Figure5

Click here to download high resolution image

Incubation

time

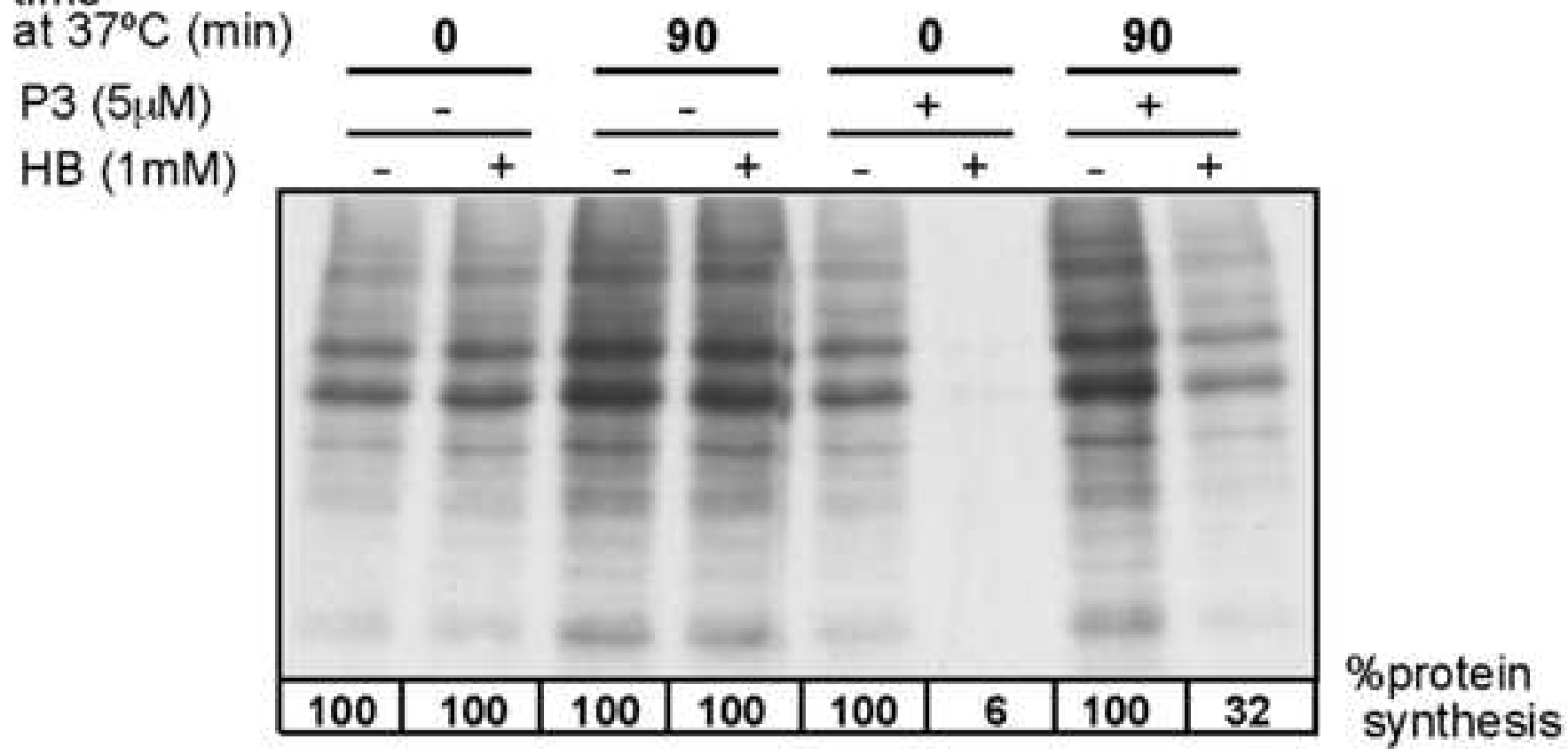


Figure
Click here to download high resolution image

A
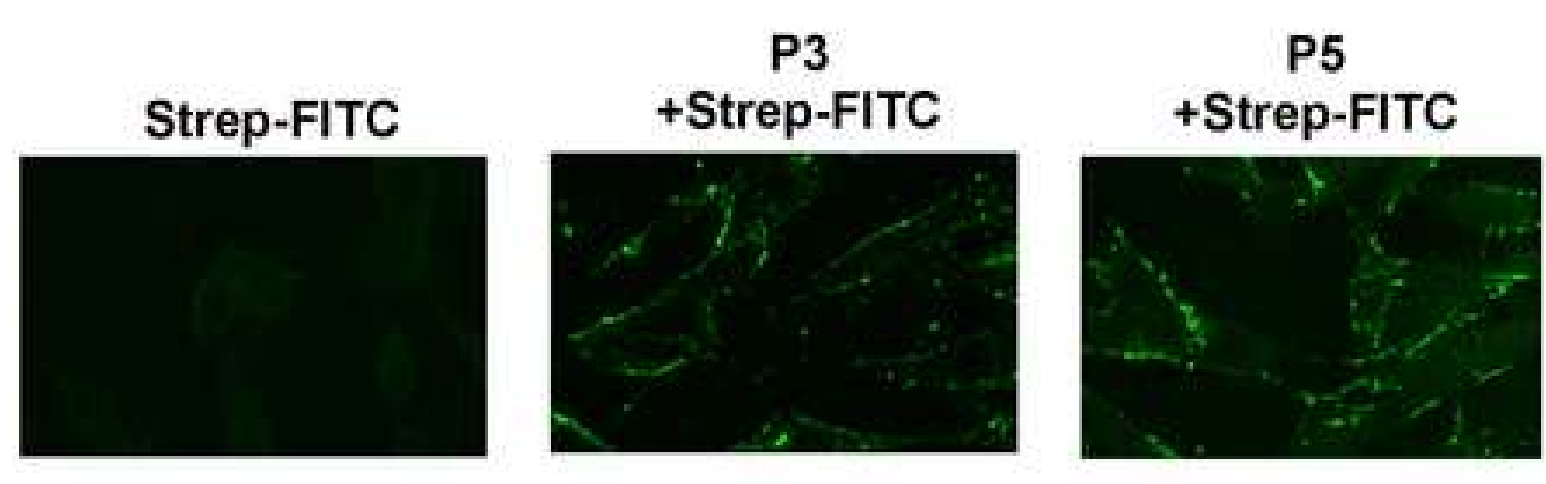

B

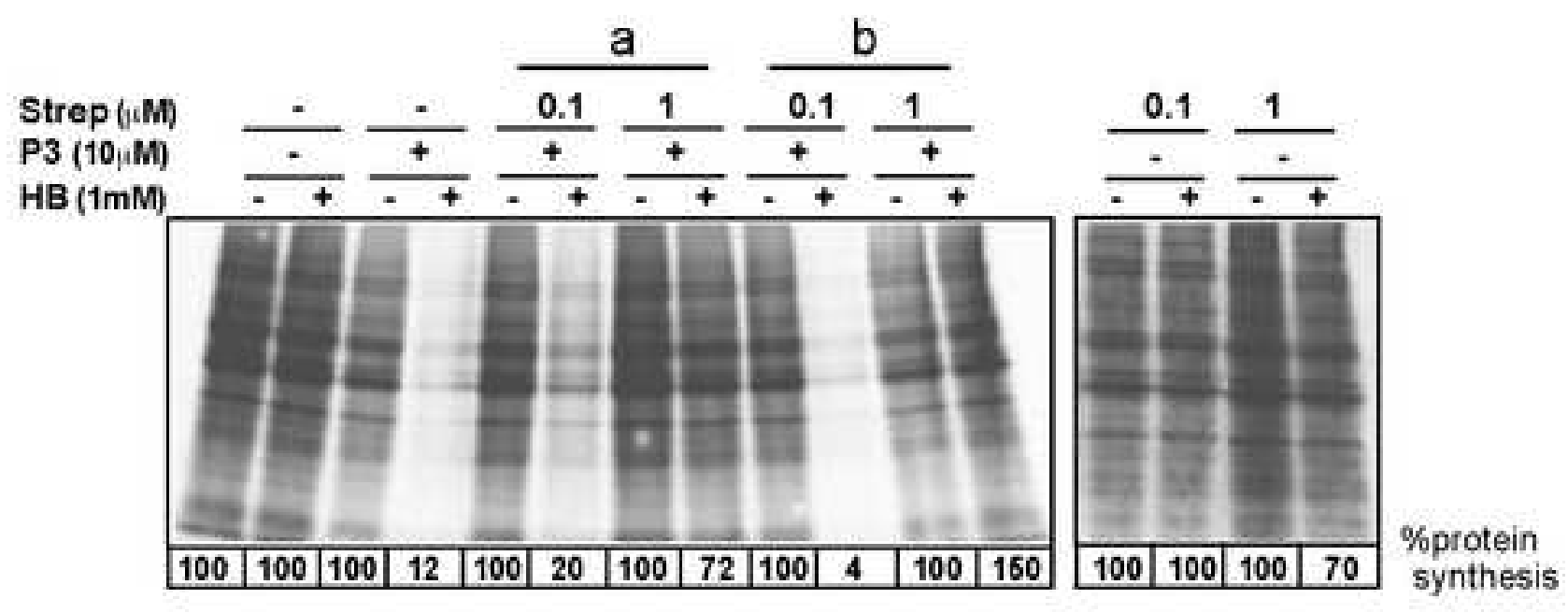

C

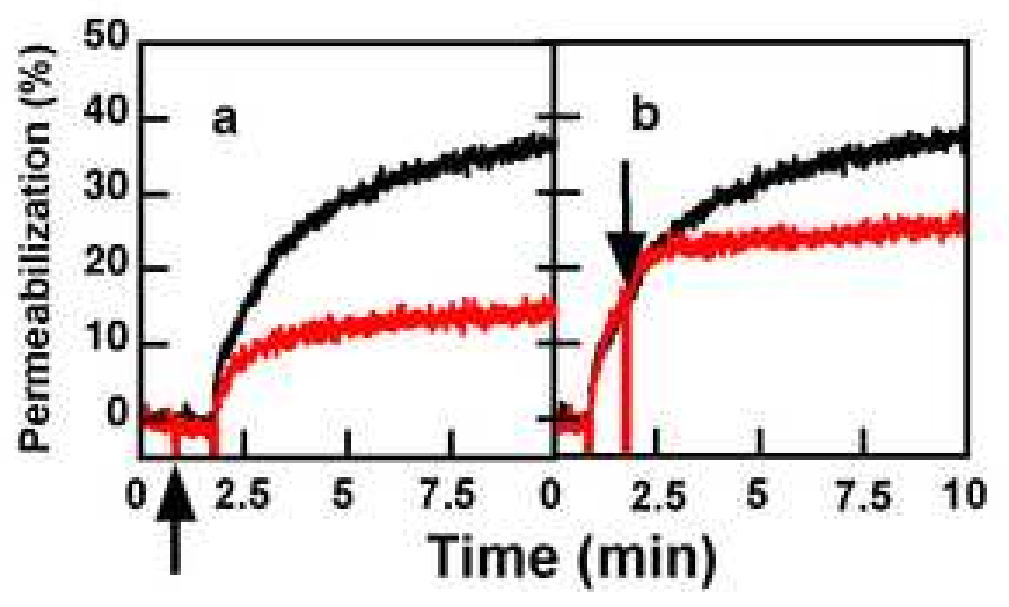


Figure
Click here to download high resolution image
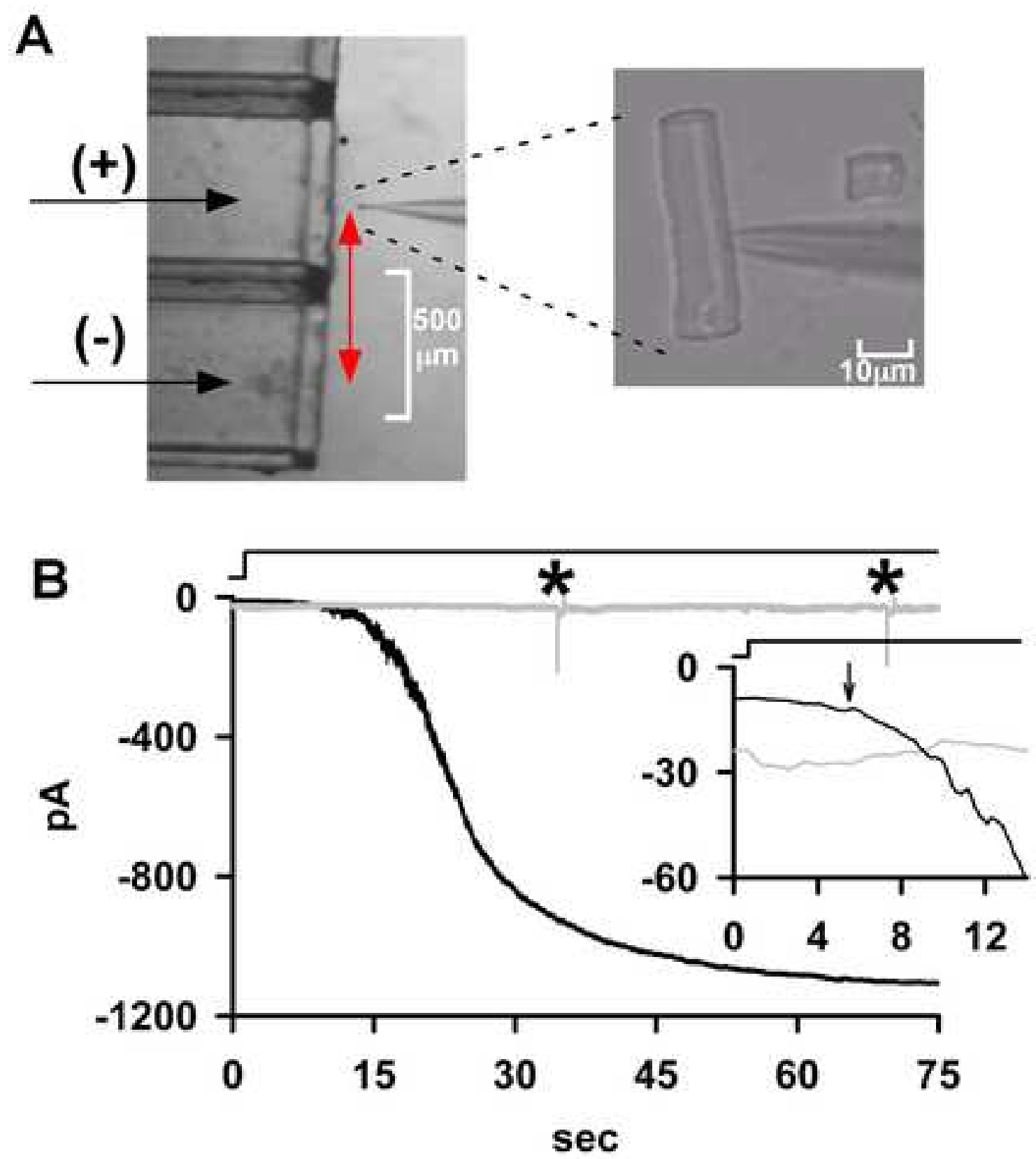

C
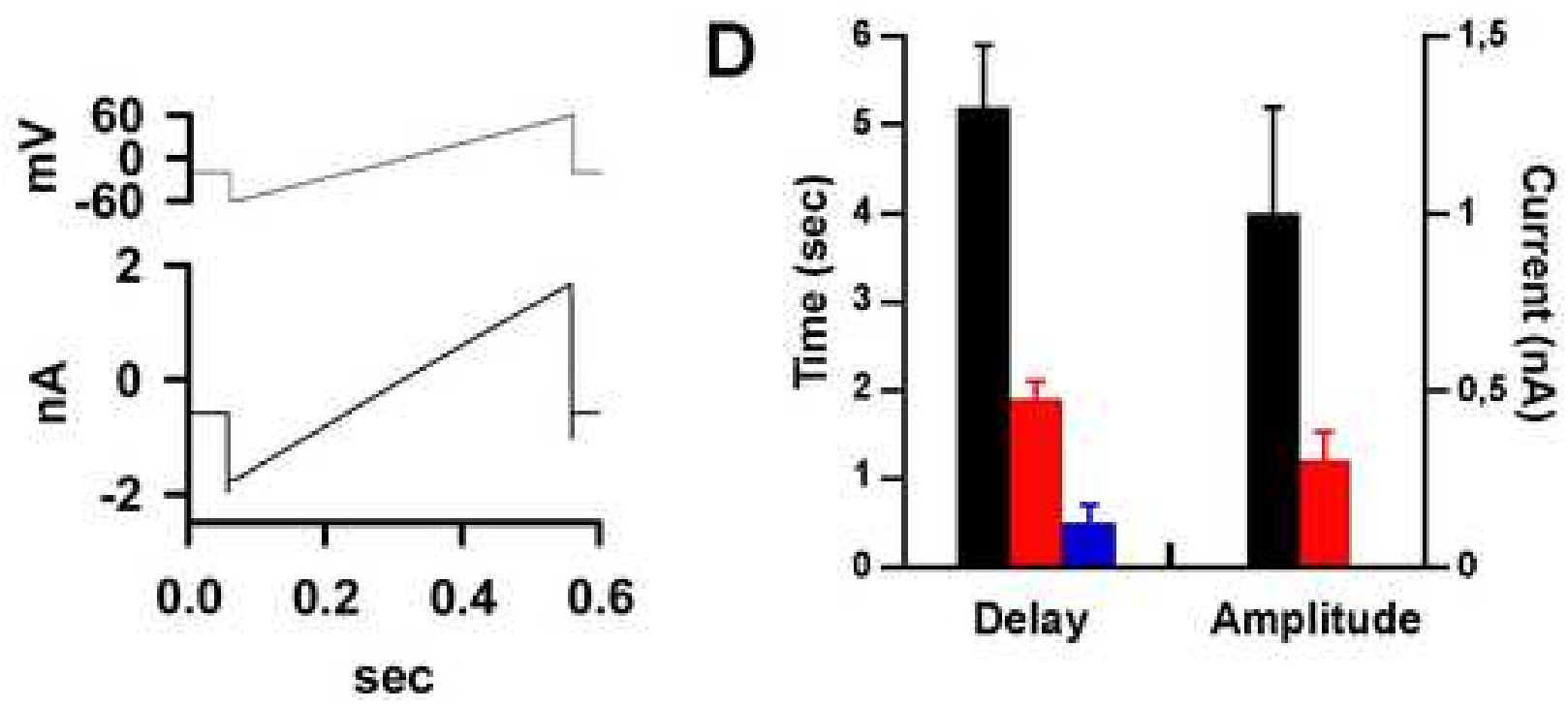
Figure8
Click here to download high resolution image

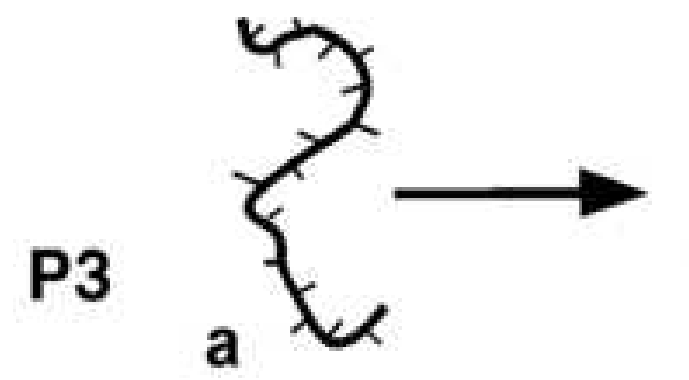

就。

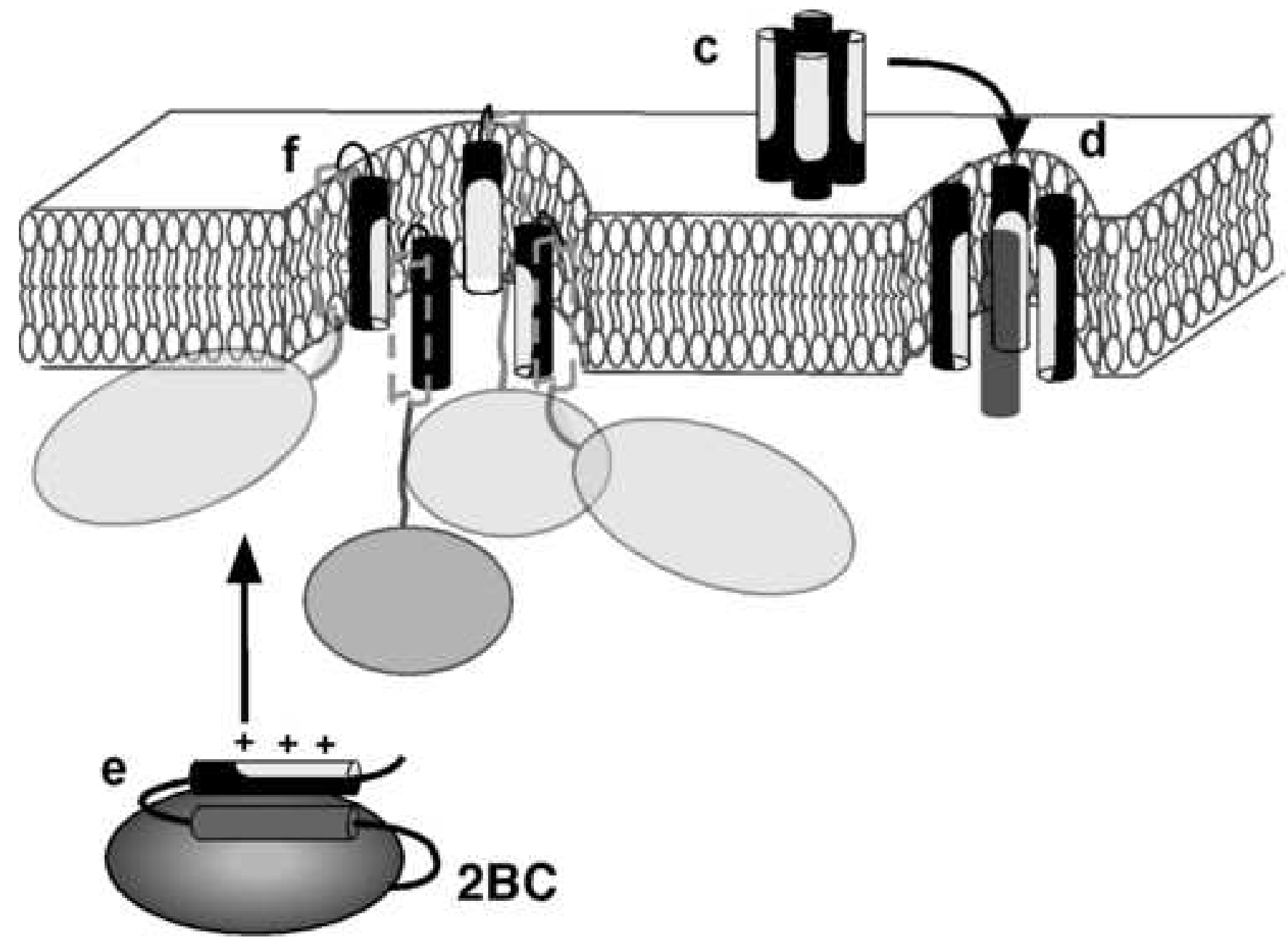

